\title{
The Protective Effects of Peroxisome Proliferator-Activated Receptor Gamma in Cerebral Ischemia-Reperfusion Injury
}

\author{
Yanping Ding ${ }^{1}$, Jie Kang ${ }^{1}$, Shuning Liu ${ }^{1}$, Yuqin $X u^{1}$ and Baoping Shao ${ }^{2 *}$ \\ ${ }^{1}$ College of Life Science, Northwest Normal University, Lanzhou, China, ${ }^{2}$ College of Life Science, Lanzhou University, \\ Lanzhou, China
}

Cerebral ischemia-reperfusion injury $(\mathrm{Cl} / \mathrm{Rl})$ is a complex pathological process that often occurs secondary to trauma, surgery, and shock. Peroxisome proliferator activated receptor gamma (PPAR $\gamma$ ) is a subunit of the PPAR and is a ligand-activated nuclear transcription factor. After being activated by its ligand, PPAR $\gamma$ can combine with specific DNA response elements to regulate the transcription and expression of genes. It has a wide range of biological functions, such as regulating lipid metabolism, improving insulin sensitivity, modulating anti-tumor mechanisms, and inhibiting inflammation. In recent

OPEN ACCESS

Edited by: Heike Wulff,

University of California, Davis, United States

Reviewed by:

Hansen Chen

Stanford University, United States

Yang Yao,

Tianjin Medical University General Hospital, China

*Correspondence: Baoping Shao

Shaobp@lzu.edu.cn

Specialty section

This article was submitted to

Stroke,

a section of the journal

Frontiers in Neurology

Received: 29 July 2020 Accepted: 16 October 2020 Published: 17 November 2020

Citation:

Ding Y, Kang J, Liu S, Xu Y and Shao B (2020) The Protective Effects of Peroxisome Proliferator-Activated Receptor Gamma in Cerebra Ischemia-Reperfusion Injury.

Front. Neurol. 11:588516. doi: 10.3389/fneur.2020.588516 years, some studies have shown that PPAR $\gamma$ exerts a protective effect during $\mathrm{Cl} / \mathrm{RI}$. This article aims to summarize the research progress of studies that have investigated the protective effects of PPARy in $\mathrm{Cl} / \mathrm{RI}$ and the cellular and molecular mechanisms through which these effects are modulated, including inhibition of excitatory amino acid toxicity, reduced $\mathrm{Ca}^{2+}$ overload, anti-oxidative stress, anti-inflammation, inhibition of microglial activation, maintain the BBB, promotion of angiogenesis, and neurogenesis and anti-apoptotic processes.

Keywords: cerebral ischemia-reperfusion, peroxisome proliferator-activated receptor $\gamma$, anti-inflammation, anti-oxidative stress, microglia activation, anti-apoptosis

\section{INTRODUCTION}

Cerebral ischemia-reperfusion injury (CI/RI) is a pathological process characterized by an initial restriction of blood supply to the brain, followed by the subsequent restoration of perfusion along with concomitant reoxygenation, resulting in severe damage to brain tissue (1). CI/RI is a very common pathophysiological phenomenon in the clinic, and is commonly observed in patients with traumatic injuries or in association with certain disease processes; some examples include hemorrhagic shock, severe surgical trauma, tumor resection, and tissue/organ transplantation (2). $\mathrm{CI} / \mathrm{RI}$ is associated with certain characteristics that include high degrees of morbidity, disability, and mortality, and a high recurrence rate, which exerts a heavy burden on the patient's family and society as a whole (3). At present, the cellular and molecular mechanisms through which CI/RI occurs have not been fully elucidated, but CI/RI is believed to be related to the production of oxidative free radicals, mitochondrial damage, disorders of energy metabolism, $\mathrm{Ca}^{2+}$ overload, and excitotoxicity (4). These pathological processes aggravate neuroinflammation and promote the activation of microglia, which is followed by the production of multiple pro-inflammatory mediators, such as cytokines, and chemokines involved in inducing changes in blood-brain barrier (BBB) permeability, causing edema, apoptosis, or necrosis. 
Peroxisome proliferator-activated receptors (PPARs) are ligand-inducible nuclear transcription factors that belong to the type II nuclear receptor superfamily. PPARs include three heterologous forms, namely $\operatorname{PPAR} \alpha, \operatorname{PPAR} \beta / \delta$, and $\operatorname{PPAR} \gamma$, with PPAR $\gamma$ being the most intensively studied to date (5). $\operatorname{PPAR} \gamma$ is widely distributed throughout the body, mainly in adipose tissue, but it is also expressed in small amounts in the spleen and liver, in monocytes/macrophages, B cells, $\mathrm{T}$ cells, and smooth muscle cells (6). In the nervous system, PPAR $\gamma$ is expressed in neurons and glia, including microglia and astrocytes, in multiple brain regions (7). When activated by its ligands, PPAR $\gamma$ can bind to specific DNA-response elements to regulate gene transcription and expression, thereby modulating a variety of physiological functions, including participating in lipid and glucose metabolism, improving insulin sensitivity, and promoting adipocyte differentiation (8).

Recent studies have shown that PPAR $\gamma$ exerts neuroprotective effects in CI/RI by downregulating proinflammatory mediators, modulating selective activation of immune cells, inducing antioxidant expression, participating in the proliferation, and differentiation of neuronal stem cells, increasing the expression of vascular endothelial growth factor (VEGF), maintaining the BBB, and reducing the expression of apoptotic factors (7). At present, PPARs agonists have been used in clinical trials mainly for the treatment of hyperlipidemia, diabetes and metabolic syndrome, and achieved results. A national cohort study showed that Asian patients with ischemic stroke taking pioglitazone for type 2 diabetes mellitus (T2DM) could lower the risks of recurrent ischemic stroke during the long term follow-up. And their data provided the evidence of pioglitazone for secondary prevention of ischemic stroke in Asian T2DM patients, which provides a theoretical basis for the development of new cardiovascular and cerebrovascular disease drugs (9). The research progress of PPAR $\gamma$ agonists in the treatment of $\mathrm{CI} / \mathrm{RI}$ in the last 5 years is summarized in the Table 1 (10-26).

In this review, we summarize major progress made to date toward understanding the neuroprotective mechanism exerted by PPAR $\gamma$ in $\mathrm{CI} / \mathrm{RI}$ in terms of its involvement in reducing glutamate toxicity and $\mathrm{Ca}^{2+}$ overload, anti-oxidative stress, anti-inflammation, including its role in inhibiting microglial activation, maintaining the $\mathrm{BBB}$, promoting angiogenesis and neurogenesis, and anti-apoptotic processes.

\section{THE ROLE OF PPAR $\gamma$ IN REDUCING GLUTAMATE-INDUCED TOXICITY AND $\mathrm{Ca}^{2+}$ OVERLOAD DURING CI/RI}

Glutamate (Glu) is one of the most widely distributed excitatory amino acids (EAAs) in the central nervous system (CNS) (4), and it plays an important role in the development and maturation of various cells under normal physiological conditions. However, excessive levels of glutamate in the intercellular space after cerebral ischemia-hypoxia leads to overexcitation of glutamate receptors, which mediate the toxic effects of EAAs, including neuronal death and oligodendrocyte damage $(4,27)$. Following acute and chronic CNS insults, N-methyl-D-aspartic acid
(NMDA) receptor-mediated neurotoxicity results in the production of oxygen free radicals and NO (28). These effects lead to decreased membrane permeability, increased $\mathrm{Ca}^{2+}$ influx, calcium overload, reactive oxygen species (ROS) aggregation, mitochondrial injury, increased BBB permeability, and cytotoxic brain edema, all of which result in the induction of cellular necrosis and apoptosis (4). The mechanism for maintaining extracellular glutamate concentrations below excitotoxic levels in the CNS is the upregulation of a certain glutamate transporter protein expressed on astrocytes, known as excitatory amino acid transporter 2 (EAAT2), which is responsible for clearing up to $90 \%$ of all extracellular glutamate (27). Therefore, the upregulation of glutamate transporter 1 (GLT1)/EAAT2 and other glutamate transporter proteins after cerebral ischemia and hypoxia may have significant benefits.

Recent studies have shown that PPAR $\gamma$ activation can play important roles in all the processes mentioned above. For example, Romera et al. (29) showed that ischemic preconditioning caused an increase in nuclear PPAR $\gamma$ transcriptional activity in neurons and astrocytes in neuronalastrocytic co-cultures, and the PPAR $\gamma$ agonist rosiglitazone increased both GLT-1/EAAT2 mRNA and protein expression and glutamate uptake, and reduced oxygen-glucose deprivation (OGD)-induced cell death and glutamate release. In addition, the PPAR $\gamma$ agonist rosiglitazone protects oligodendrocyte precursor cells (OPCs) and oligodendrocytes by regulating the glutamate transporter proteins GLT1/EAAT2 to blunt the extent of excitotoxic injuries (30). According to the research, telmisartan, an angiotensin-receptor blocker (ARB) drug, also upregulates pigment epithelium-derived factor (PEDF) by activating PPAR $\gamma$ after middle cerebral artery occlusion (MCAO), and improves the associated neurological deficits, reduces cerebral edema, promotes the expression of glutamate transporters [both GLT-1 and glutamate-aspartate transporter (GLAST)], and reduces the activation of microglia and the expression of pro-inflammatory factors such as interleukin 1 $\beta$ (IL-1 $\beta$ ), interleukin 6 (IL-6), tumor necrosis factor alpha (TNF- $\alpha$ ), cyclooxygenase-2 (COX-2), and inducible nitric oxide synthase (iNOS) (31). Garcia-Bueno et al. (32) reported that treatment with PPAR $\gamma$ agonists exerted a direct protective effect on cerebral glucose and glutamate metabolism, and PPAR $\gamma$ agonists reduced oxidative damage in the brain under stress by increasing the expression of neuronal glucose transporter protein 3 (GLUT-3) and by regulating EAAT-2.

Calcium overload causes CI/RI, and there are several key mechanisms responsible for the changes: (i) increased activity of mitochondrial calcium pumps and excessive intake of $\mathrm{Ca}^{2+}$ leads to increased adenosine triphosphate (ATP) consumption, the opening of mitochondrial permeability transition pores, the interference of mitochondrial oxidative phosphorylation, and ultimately mitochondrial dysfunction; (ii) the increased intracellular $\mathrm{Ca}^{2+}$ concentration activates a variety of phospholipases, which promote the decomposition of membrane phospholipids, followed by structural damage to the cell and organelle membranes; (iii) the increased intracellular $\mathrm{Ca}^{2+}$ promotes the generation of oxygen free radicals by enhancing the activity of $\mathrm{Ca}^{2+}$-dependent protein kinase 
TABLE 1 | Summation of the research progress of PPAR $\gamma$ agonists in the treatment of $\mathrm{Cl} / \mathrm{Rl}$ in the last 5 years.

\begin{tabular}{|c|c|c|c|c|c|}
\hline Ligand & Model & $\begin{array}{l}\text { Treatment time points } \\
\text { and dose }\end{array}$ & Molecular & Treatment outcomes & References \\
\hline \multirow[t]{3}{*}{ Pioglitazone (PGZ) } & $\begin{array}{l}\text { BCCAO for } 30 \text { mins }+ \\
\text { reperfusion for } 24 \mathrm{~h} \text { (rat) }\end{array}$ & $\begin{array}{l}14 \text { days prior MCAO, } 10 \\
\mathrm{mg} / \mathrm{kg} / \mathrm{d} \text {, p.o. }\end{array}$ & $\begin{array}{l}\text { Reduced MDA, TNF- } \alpha \text {, iNOS, } \\
\text { and caspase } 3 \text { expression; } \\
\text { Increased glutathione } \\
(\text { GSH) expression }\end{array}$ & $\begin{array}{l}\text { Anti-inflammatory; } \\
\text { Anti-apoptosis; } \\
\text { Improved the neurological } \\
\text { functions; } \\
\text { Reduce morphological damage }\end{array}$ & (10) \\
\hline & $\begin{array}{l}\text { MCAO for } 90 \text { mins + } \\
\text { ovariectomized rat }\end{array}$ & $\begin{array}{l}7-14 \text { days after MCAO, } \\
2.5 \mathrm{mg} / \mathrm{kg} / \mathrm{d} \text {, i.p. }\end{array}$ & $\begin{array}{l}\text { Activation of Akt, MAP2, and } \\
\text { VEGF }\end{array}$ & $\begin{array}{l}\text { Anti-inflammatory; Promote } \\
\text { regeneration }\end{array}$ & (12) \\
\hline & $\begin{array}{l}\text { MCAO for } 90 \text { mins and } \\
\text { reperfusion for } 24 \mathrm{~h} \text { (rat) }\end{array}$ & $\begin{array}{l}3 \text { days after reperfusion, } \\
10 \mathrm{mg} / \mathrm{kg} / \mathrm{d} \text {, p.o. }\end{array}$ & $\begin{array}{l}\text { Reduced caspase } 1, \text { NLRP3, } \\
\text { IL- } 1 \beta \text {, and IL-18 expression }\end{array}$ & $\begin{array}{l}\text { Anti-inflammatory; } \\
\text { Anti-apoptosis }\end{array}$ & (13) \\
\hline \multirow[t]{3}{*}{ Rosiglitazone (RSG) } & $\begin{array}{l}\mathrm{MCAO} \text { for } 2 \mathrm{~h}+ \\
\mathrm{tPA} \text {-induced hemorrhagic } \\
\text { transformation ( } 2 \mathrm{~h} \text { after } \\
\mathrm{MCAO} \text { ) (mouse) }\end{array}$ & $\begin{array}{l}1 \mathrm{~h} \text { prior MCAO, } 6 \mathrm{mg} / \mathrm{kg} \text {, } \\
\text { i.p. }\end{array}$ & $\begin{array}{l}\text { Attenuates HT and BBB } \\
\text { disruption; Reduced iNOS } \\
\text { expression; Increased CD206 } \\
\text { expression }\end{array}$ & $\begin{array}{l}\text { Regulate microglial phenotype } \\
\text { Reduce morphological damage }\end{array}$ & (15) \\
\hline & $\begin{array}{l}\text { OGD/R for } 10 \mathrm{~h} \text { reperfusion } \\
\text { for } 24 \mathrm{~h} \text { ( } \mathrm{PC} 12 \text { cells) }\end{array}$ & $10 \mathrm{~h}$ after OGD, $10 \mu \mathrm{mol}$ & $\begin{array}{l}\text { Reduced HMGB1 expression } \\
\text { Increased DUSP8 and Bcl-xl } \\
\text { expression }\end{array}$ & $\begin{array}{l}\text { Anti-inflammatory; } \\
\text { Anti-apoptosis }\end{array}$ & (16) \\
\hline & $\begin{array}{l}\text { Spontaneousintracerebral } \\
\text { hemorrhage }(\mathrm{ICH})(\text { rat) }\end{array}$ & $\begin{array}{l}3 \text { days prior } \mathrm{MCAO}+1 \mathrm{~h}, 2 \\
\text { days and } 3 \text { days after } \\
\mathrm{MCAO}, 3 \mathrm{mg} / \mathrm{Kg} / \mathrm{d} \text {, p.o. }\end{array}$ & Increased CD36 expression & $\begin{array}{l}\text { Activate phagocytic ability of } \\
\text { microglia; } \\
\text { Improved the neurological } \\
\text { functions }\end{array}$ & (17) \\
\hline $\begin{array}{l}\text { Propane-2-sulfonic } \\
\text { acid } \\
\text { octadec-9-enyl-amide } \\
\text { (N15) }\end{array}$ & MCAO for $2 \mathrm{~h}$ (rat) & $\begin{array}{l}2-13 \text { days after MCAO; } \\
100 \text { mg/kg/d, p.o. }\end{array}$ & $\begin{array}{l}\text { Increased GAP- } 43 \text {, } \\
\text { synaptophysin(SYP), BDNF, and } \\
\text { NT-3 expression in the } \\
\text { hippocampus }\end{array}$ & Promote regeneration & (18) \\
\hline Oleic acid (OA) & $\begin{array}{l}\text { MCAO for } 90 \text { mins (rat); } \\
\text { Photothrombosis } 15 \text { mins } \\
\text { (mouse); Four-vessel } \\
\text { occlusion (4-VO) } 10 \text { mins } \\
\text { (rat) }\end{array}$ & $\begin{array}{l}0,2 \text {, and } 3 \mathrm{~h} \text { after surgery, } \\
\text { 10,30 } \mathrm{mg} / \mathrm{kg} \\
\text { 20,60, } 200 \mathrm{mg} / \mathrm{kg} \\
\text { 1, 30, } 10 \mathrm{mg} / \mathrm{kg} \text {, i.p. }\end{array}$ & $\begin{array}{l}\text { Reduced COX-2, iNOS, and } \\
\text { TNF- } \alpha \text { expression }\end{array}$ & $\begin{array}{l}\text { Anti-inflammatory; } \\
\text { Anti-apoptosis; } \\
\text { Promote cognition; } \\
\text { Reduce morphological damage }\end{array}$ & (20) \\
\hline $\begin{array}{l}10-\mathrm{O}-(\mathrm{N}, \mathrm{N}- \\
\text { dimethylaminoethyl)- } \\
\text { ginkgolide B } \\
\text { methanesulfonate(XQ- } \\
\text { 1H) }\end{array}$ & $\begin{array}{l}\text { MCAO + reperfusion for } 1 \\
\text { or } 3 \text { days (mouse); OGD/R } \\
\text { for } 3 \mathrm{~h} \text { (BV-2 microglia) }\end{array}$ & $\begin{array}{l}\text { 1, } 3 \text { days after MCAO, TID, } \\
31,62 \mathrm{mg} / \mathrm{kg}, \mathrm{p} . \mathrm{O} ; \\
24 \mathrm{~h} \text { before OGD/R, 1, 3, } \\
10 \mu \mathrm{M}\end{array}$ & $\begin{array}{l}\text { Regulation of microglia } \\
\text { polarization }\end{array}$ & $\begin{array}{l}\text { Anti-inflammatory; Promote } \\
\text { cognition; Anti-oxidation; } \\
\text { Reduce morphological damage; } \\
\text { Regulate microglial phenotype }\end{array}$ & (21) \\
\hline Telmisartan (TEL) & MCAO for $2 \mathrm{~h}$ (rat) & $\begin{array}{l}3 \text { weeks after MCAO, } \\
1,5,10 \mathrm{mg} / \mathrm{kg} / \mathrm{d}\end{array}$ & $\begin{array}{l}\text { Reduced MMP2, MMP9, and } \\
\text { acetylcholinesterase (AChE) } \\
\text { expression; } \\
\text { Increased choline } \\
\text { acetyltransferase (ChAT) and } \\
\text { SYN expression }\end{array}$ & $\begin{array}{l}\text { Promote regeneration; } \\
\text { Promote cognition }\end{array}$ & (22) \\
\hline Ginsenoside Rg1 & $\begin{array}{l}\text { MCAO for } 90 \text { mins and } \\
\text { reperfusion for } 24 \mathrm{~h} \text { (rat); } \\
\text { OGD for } 90 \text { mins } \\
\text { reperfusion for } 24 \mathrm{~h} \\
\text { (neurons) }\end{array}$ & $\begin{array}{l}6 \mathrm{~h} \text { after reperfusion, } \\
\text { 30, } 60 \mathrm{mg} / \mathrm{kg} \text { i.p.; } \\
30,60 \mu \mathrm{mol} / \mathrm{L}\end{array}$ & $\begin{array}{l}\text { Reduced TNF- } \alpha, \text { IL-6,NF-kB, } \\
\text { and MPO expression; } \\
\text { Increased antioxidant enzymes } \\
\text { SOD and CAT expression }\end{array}$ & $\begin{array}{l}\text { Anti-inflammatory; Anti-oxidation } \\
\text { Reduce morphological damage }\end{array}$ & (23) \\
\hline
\end{tabular}


TABLE 1 | Continued

\begin{tabular}{|c|c|c|c|c|c|}
\hline Ligand & Model & $\begin{array}{l}\text { Treatment time points } \\
\text { and dose }\end{array}$ & Molecular & Treatment outcomes & References \\
\hline $\begin{array}{l}15- \\
\text { hydroxyeicosatetraenoic } \\
\text { acid (15-HETE) }\end{array}$ & $\begin{array}{l}\text { MCAO for } 1 \mathrm{~h} \text { and } \\
\text { reperfusion for } 24 \mathrm{~h} \text { (rat) }\end{array}$ & $\begin{array}{l}30 \text { mins prior MCAO, } 15 \mu \mathrm{l} \text {, } \\
\text { icv. }\end{array}$ & $\begin{array}{l}\text { Reduced MDA expression; } \\
\text { Increased SOD expression }\end{array}$ & $\begin{array}{l}\text { Anti-apoptosis; Anti-oxidation; } \\
\text { Reduce morphological damage }\end{array}$ & (24) \\
\hline Liraglutide & $\begin{array}{l}\text { MCAO with diabetes } \\
\text { mellitus (rat) }\end{array}$ & $\begin{array}{l}7 \text { days prior MCAO, BID, } \\
100 \mu \mathrm{g} / \mathrm{kg} \text {, i.p. }\end{array}$ & $\begin{array}{l}\text { Reduced TNF- } \alpha \text { and NF-кB } \\
\text { expression }\end{array}$ & $\begin{array}{l}\text { Anti-inflammatory; Decreased } \\
\text { glucose }\end{array}$ & (25) \\
\hline 15d-PGJ2 & $\begin{array}{l}\text { MCAO with diabetes } \\
\text { mellitus (rat) }\end{array}$ & $\begin{array}{l}21 \text { days prior } \mathrm{MCAO}+3 \mathrm{~h} \text {, } \\
6 \text { days after } \mathrm{MCAO}, 200 \\
\mu \mathrm{g} / \mathrm{kg} / \mathrm{d} \text {, i.p. }\end{array}$ & $\begin{array}{l}\text { Reduced of CD68, TNF- } \alpha \text {, and } \\
\text { IL-1 } 1 \beta \text { expression }\end{array}$ & $\begin{array}{l}\text { Anti-inflammatory; } \\
\text { Anti-apoptosis; } \\
\text { Inhibit microglial activation }\end{array}$ & (26) \\
\hline
\end{tabular}

(CaMK), and the interaction between $\mathrm{ROS}$ and $\mathrm{Ca}^{2+}$ lasts for hours or even days after cerebral ischemia, eventually triggering cell death $(33,34)$.

Studies have shown that berberine reduced calcium overload caused by cerebral ischemia by mediating PPAR $\gamma$ (35). The PPAR $\gamma$ activator G-Rg1 downregulates the increased free radical concentrations induced by excessive Glu and asparaginic acid (Asp) levels, inhibits the influx of extracellular calcium as well as neuronal NOS (nNOS) activity, and attenuates ischemic nerve damage and its associated apoptotic effects (such as further intracellular calcium overload, alpha-aminoadipic acid (AAA; a glutamate analog) toxicity, energy metabolism disorder, and mitochondrial apoptosis) via its effects on NMDA receptors, endoplasmic reticulum (ER) stress, and the 5' AMP-activated protein kinase (AMPK)-associated AMP/AMPKGLUT pathways (4).

In summary, PPAR $\gamma$ can reduce $\mathrm{Ca}^{2+}$ overload by increasing the expression of EAAT2, reducing the release of glutamate and the activation of NMDA receptors, and attenuates neuronal necrosis and apoptosis after CI/RI.

\section{THE ROLE OF PPAR $\gamma$ IN ANTI-OXIDATIVE STRESS/ANTI-ER STRESS RESPONSES DURING CI/RI}

Although oxidative stress, inflammation, and apoptosis occur concurrently in ischemic stroke, oxidative stress seems to be a potential initiator (36). ROS are produced in the early stages of CI/RI (37) and promote the expression of multiple proinflammatory mediators, including monocyte chemoattractant protein 1 (MCP-1), vascular cell adhesion molecule-1 (VCAM1 ), and IL- 6 by activating nuclear factor- $\kappa \mathrm{B}(\mathrm{NF}-\kappa \mathrm{B})$, extracellular signal-regulated protein kinases (ERK1/2), protein tyrosine kinase (PTK), and Janus kinase 2-signal transducers and activators of transcription (JAK2-STAT) $(38,39)$. In addition, the production of ROS leads to increased leakage of malonaldehyde (MDA) and lactate dehydrogenase (LDH) on intracellular biofilms, and irreversible destruction of proteins and nucleic acids (40).

Activation of nicotinamide adenine dinucleotide phosphate (NADPH) oxidase (NOX), of the non-phagocytic cell oxidase family, is a major driving force in ROS generation in the reoxygenation/reperfusion environment (41). Seven homologous members have been documented in the family: Nox1-5 and Duox1-2; among them, Nox2 was the first member to be identified and has been the most extensively studied. In its resting state, the catalytic subunit of Nox2 remains bound to the regulatory subunit of $\mathrm{p} 22$ phox [human neutrophil cytochrome $b$ light chain (CYBA)], anchored in the plasma membrane. Upon stimulation, the cytosolic subunits p47phox, p67phox, p40phox, and small Rac GTPases ( $\mathrm{rac} 1 / 2)$ are recruited to the plasma membrane where they bind to Nox $2 / \mathrm{p} 22$ phox to form the active NOX holoenzyme (41). It has been proven that a sequential neuroprotective signaling cascade activated by the PPAR $\gamma$ agonist 15d-PGJ2 reduces NF- $\kappa \mathrm{B}$ nuclear translocation to suppress the NF-кB-driven p22phox transcription and subsequent NOX activation, thereby decreasing the production of ROS (41). Rasrelated $\mathrm{C} 3$ botulinum toxin substrate 1 ( $\operatorname{Rac} 1)$, a small GTPase protein, is an essential subunit of NOX responsible for the generation of ROS, with its active form being Rac1-GTP (42). Xia et al. (11) found that the PPAR $\gamma$ agonist pioglitazone inhibited the activity of Racl, the production of ROS, and the apoptosis induced by ischemia/hypoxia in both the MCAO and in vitro OGD models, indicating that PPAR $\gamma$ inhibits the activation of Rac1/ROS signaling.

In addition to reducing the production of superoxide compounds by reducing NOX, PPAR $\gamma$ also accelerates the removal of excess superoxide molecules by increasing the production of antioxidant enzymes. Superoxide dismutase (SOD), glutathione (GSH) peroxidase (GSH-Px), and catalase (CAT) are all endogenous antioxidant enzymes that constitute the first line of the intracellular antioxidant defense system, which can inhibit free radical damage by removing excess ROS (43). The CAT and SOD gene promoters contain peroxisome proliferator response element (PPRE), indicating that they are directly regulated by $\operatorname{PPAR} \gamma(44,45)$. Furthermore, the depletion of GSH was prevented by both pioglitazone and rosiglitazone treatment in adult rats subjected to cerebral ischemia $(44,46)$. Studies have shown that ginsenoside G-Rg1 might be a potent agonist of PPAR $\gamma$, with demonstrated sensitivity and protective properties against oxidative stress in oxidative tissue injury due to its significant reduction of myeloperoxidase (MPO) activity and the normalization of the diminished expression of antioxidant enzymes SOD and CAT (23). The PPAR $\gamma$ antagonist GW9662 blocked the increase in PPAR $\gamma$ DNA binding activity and 
the antioxidant enzymatic activities of SOD and CAT, thereby abolishing the protective effect of PPAR $\gamma$ activation in the OGD model with exposed neurons (47). Shimazu et al. (48) showed that PPAR $\gamma$ activation could increase the activity of $\mathrm{Cu}-\mathrm{Zn}$ SOD and its free radical scavenging effect, reducing the levels of NO, COX-2, iNOS, and nitrotyrosine in cerebral ischemia models (49). Uncoupling proteins (UCPs) are located in the inner mitochondrial membrane that can prevent mitochondrial damage by reducing the proton gradient and ROS production through uncoupled oxidative phosphorylation. It has been shown that PPAR $\gamma$ is involved in the transcriptional regulation of UCPs (50).

In addition to oxidative stress, ER stress is also crucial to the development of CI/RI. Ischemic conditions can stimulate unfolded protein aggregation in the ER lumen, leading to the unfolded protein response (UPR). The UPR is correlated with ER membrane extension, promoting degeneration of unfolded proteins, inhibiting protein synthesis, and enhanced folding chaperon transcription. Although the ER plays an important role in restoring homeostasis, the UPR can lead to accelerated activation of cell death-promoting pathways regulated by CCAAT/enhancer binding protein (C/EBP) homologous protein (CHOP; a marker of apoptosis in ER-associated stress mechanisms), c-Jun N-terminal kinase (JNK), and caspase12 under conditions of severe or prolonged stress (51). The stimulated caspase- 12 subsequently stimulates caspase- 9 as well as caspase-3, triggers fragmentation of DNA, and ultimately causes cell death. CHOP upregulates B-cell lymphoma 2 (Bcl-2)associated $\mathrm{X}$ protein (BAX) while inhibiting Bcl-2 (52). In the in vivo $\mathrm{MCAO}$ model and in vitro Neuron $2 \mathrm{~A}$ cell line (transfected with PPAR $\gamma$-specific) OGD reperfusion model, PPAR $\gamma$-deficient cells displayed an extended infarct trigon and more severe neuron deficiency, and upregulated levels of CHOP, as well as cleaved caspase-12, and binding immunoglobulin protein (BiP) (both markers of ER stress). It has been proven that PPAR $\gamma$ protects the brain from CI/RI by suppressing ER stress (53).

In summary, PPAR $\gamma$ reduces the production of ROS by inhibiting the activity of Racl and NOX on the one hand and increasing the expression of antioxidant enzymes on the other hand, thereby reducing the cell damage caused by MDA and LDH. In addition, PPAR $\gamma$ can also against the brain from CI/RI injury by inhibiting ER stress.

\section{ANTI-INFLAMMATORY EFFECTS OF PPAR $\gamma$ IN CI/RI}

Inflammation, a critical process in CI/RI (54); it is mediated by a range of endogenous factors, including inflammatory cytokines [IL-1, IL-6, TNF- $\alpha$, interferon gamma (IFN- $\gamma$ ), etc.], lipid mediators, and eicosanoids, including prostaglandins, leukotrienes, and lipoxin (55). Inflammatory cascade reactions gradually induce apoptosis in the peri-ischemic region of the brain (54). PPAR $\gamma$ agonists can inhibit inflammation induced by $\mathrm{CI} / \mathrm{RI}$ by competitively inhibiting the production of inflammatory factors and their signaling pathways (56); more specifically, by modulating the JAK-STAT proteins, NF- $\mathrm{B}$, nuclear factor of activated T-cells (NFAT), and activator protein 1 (AP-1) pathways, which regulate the expression of nuclear factor erythroid 2-related factor 2 (Nrf2), nucleotide oligomerization domain (NOD)-like receptor protein 3 (NLRP3), and high mobility group box protein 1 (HMGB1) (Figure 1).

\section{PPAR $y$ Inhibits the JAK-STAT Pathway and Increases Suppressor of Cytokine Signaling (SOCS) Protein Expression}

It has been shown that CI/RI can induce the release of a large number of inflammatory cytokines, such as IL-1, IL6 , TNF- $\alpha$, and IFN- $\gamma$. These factors can activate the JAKSTAT signaling pathway and produce inflammation (57). The specific mechanism responsible for this process is that a variety of extracellular inflammatory cytokines bind to the corresponding receptors on the membrane as ligands, causing the receptor-coupled JAK to aggregate and be activated by phosphorylation, resulting in the subsequent phosphorylation and activation of transcriptional activation factor STAT (44). Activated STAT leaves the receptor and dimerizes to form a homodimer/heterodimer that translocates into the nucleus to bind to the coactivator cyclic adenosine monophosphate response element-binding protein (CREB)-binding protein (CBP) or p300. There, it can then bind to the promoter of the target gene, thereby activating its expression. The STAT family has seven members that mediate the transcription of multiple cytokines: Stat 1 and Stat 2 are required for IFN $-\gamma$ to regulate gene expression; Stat 3 is required for gene expression in IL-6induced acute phase responses; STAT1 and STAT3 can reduce the expression of anti-apoptotic genes [Bcl-2 and B-cell lymphoma extra-large $(\mathrm{Bcl}-\mathrm{xl})]$, leading to neuronal apoptosis. As a target gene of STATs, the SOCS protein can inhibit their activation directly or inhibit the activation of JAKs, specifically, by binding to JAKs or associated receptors, thus playing a regulatory role through negative feedback $(44,58)$.

A study reported that activated PPAR $\gamma$ forms an isomeric dimer with the retinoid $\mathrm{X}$ receptor (RXR), known as PPAR $\gamma$ RXR. This dimer binds CBP and p300 through competition and recruitment, thereby inhibiting STAT1 activation and blocking the production of STAT1-related proinflammatory factors (IL6, IL-1, and TNF- $\alpha$ ) (59). PPAR $\gamma$ agonists can inhibit the phosphorylation of JAK1/2 and STAT1/3 in the reperfusion zone of ischemia-reperfusion (IR)-injured rats, decrease their neurological score, and reduce the IR injury in brain tissue $(5,58)$. In addition, PPAR $\gamma$ inhibits the JAK-STAT pathway by promoting the expression of SOCS, and studies have shown that the PPAR $\gamma$ agonists 15d-PGJ2 and rosiglitazone are effective inducers of SOCS. Treatment with rosiglitazone can induce the expression of SOCS3 and prevent phosphorylation of JAK2 and STAT3 $2 \mathrm{~h}$ after focal IR, thereby playing a neuroprotective role $(49,60)$.

\section{PPAR $\gamma$ Inhibits the NF- $\kappa$ B Pathway}

$\mathrm{CI} / \mathrm{RI}$ can also initiate activation of the NF- $\kappa \mathrm{B}$ pathway.

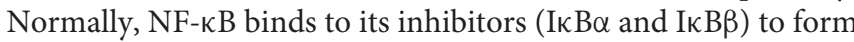
a trimer, which is distributed throughout the cytoplasm in an 


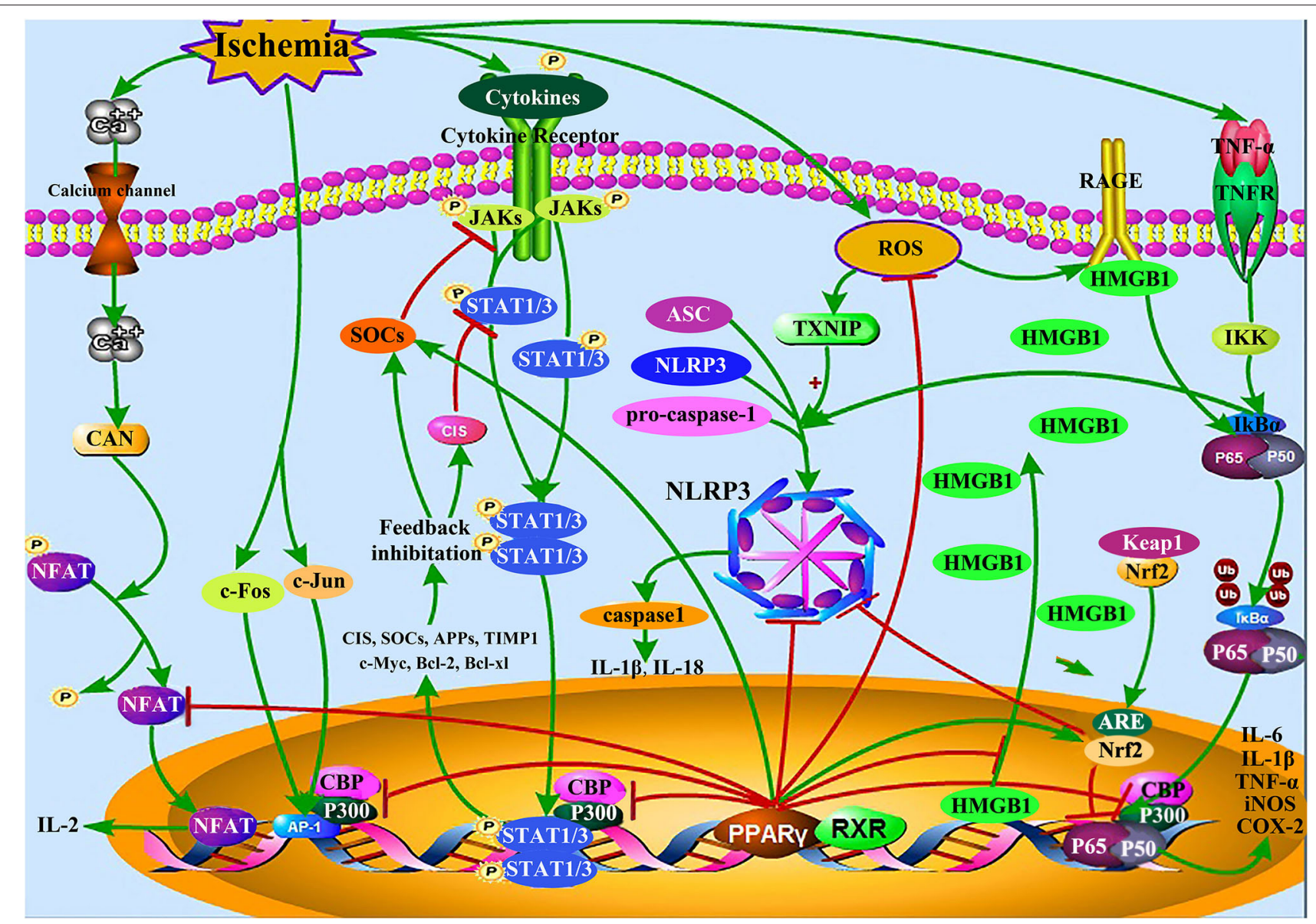

FIGURE 1 | Inflammation-related signaling pathways in CI/RI mediated by PPAR $\gamma$. PPAR $\gamma$ competitively inhibits JAK-STAT, NF-KB, AP-1, NFAT, HMGB1/RAGE, and other inflammation-related signaling pathways, up-regulates the expression of Nrf2, and SOCS protein, reduces the expression of NLRP3 inflammasome and pro-inflammatory mediator including IL-1 $\beta$, IL-6, and TNF- $\alpha$, thereby reducing the Cl/RI injury caused by inflammation.

inactive state (59). In inflammation induced by CI/RI, the TNF receptor-associated factor (TRAF) protein family induces the activation of inhibitor of NF- $\mathrm{KB}$ (IКB) kinase (IKK), leading to the phosphorylation of ІкB proteins and the subsequent dissociation of IкB from the heterotrimeric p50/p65/IkB complex, which is degraded by the proteasome after ubiquitination, ultimately resulting in the activation of NF- $\mathrm{B}$. Free NF- $\mathrm{kB}$ then enters the nucleus and binds to $\mathrm{p} 300 / \mathrm{CBP}$, followed by specific binding to certain $\mathrm{kB}$ sites on DNA to induce transcription and expression of related genes, including proinflammatory cytokines such as IL-1 $\beta$, IL- 6 , and TNF- $\alpha$, and neuroinflammatory genes such as COX-2 and iNOS $(56,59,61)$. Among these, COX-2 is an enzyme that aggravates the changes induced by $\mathrm{CI} / \mathrm{RI}$ and promotes the conversion of arachidonic acid to prostaglandin $\mathrm{H} 2$ (PGH2), which produces prostaglandin E2 (PGE2), and participates in the inflammatory response (60).

Several in vivo and in vitro studies have shown that PPAR $\gamma$ reduces the release of proinflammatory cytokines in CI/RI models by inhibiting the NF- $\mathrm{BB}$ pathway (56). PPAR $\gamma$ binds to the P65/P50 subunit of NF- $\mathrm{kB}$ directly to form a transcriptional inhibitory complex that reduces the binding activity of NF- $\mathrm{\kappa B}$ at DNA sites, thereby inhibiting the production of downstream inflammatory factors. PPAR $\gamma$ also inhibits NF- $\mathrm{kB}$ transcription by competitively binding the coactivator p300 and CBP (59). The PPAR $\gamma$ agonist 15dPGJ2 mediates its anti-inflammatory effects by inducing binding of PPAR $\gamma$ to IKK directly, thereby inactivating it (62). As a novel PPAR $\alpha / \gamma$ dual agonist, N15 can enhance $P P A R \alpha / \gamma$ signal transduction and inhibit the activation of the NF- $\kappa \mathrm{B}$ signaling pathway, thus playing an antiinflammatory role that relieves brain damage after CI/RI (19).

\section{PPAR $\gamma$ Regulates the Expression of Nrf2}

Nrf2 is an important transcription factor that mediates oxidative stress. Physiologically, Nrf2 binds to the cytoplasmic adaptor protein Kelch-like ECH-associated protein 1 (Keap1) to inhibit its activity. In ischemia-induced oxidative stress, Nrf2 uncouples from Keap1 and translocates into the nucleus where it interacts with the anti-oxidative response element (ARE) to induce the expression of downstream protective phase II detoxifying enzymes and antioxidant enzymes to achieve cytoprotective effects. There is increasing evidence that activation of the Nrf2 pathway significantly inhibits NF- $\mathrm{\kappa B}$ and that it plays a protective 
role in the inflammatory response (63). Nrf2 and PPAR $\gamma$ genes are mutually regulated. First, the Nrf2 gene sequence contains the PPRE, while the PPAR $\gamma$ gene sequence contains the Nrf2-specific response element (i.e., ARE). Second, PPAR $\gamma$ and Nrf2 share some common target genes. For example, the DNA sequence of CAT contains both ARE and PPRE, which can be regulated by Nrf2 and PPAR $\gamma$ at the same time to enhance the expression of CAT. Third, both PPAR $\gamma$ and Nrf2 regulate NF- $\kappa B$ negatively, thus inhibiting NF-кB synergistically (64). Furthermore, in an in vitro $\mathrm{CI} / \mathrm{RI}$ model, microglial Nrf2 plays a negative role in the activation of the NLRP3 inflammasome (65).

Huang et al. (66) found that ginsenoside G-Rg1, an effective activator of PPAR $\gamma$, downregulated Nrf2 levels in the cytoplasm and upregulated Nrf2 levels in the nucleus. A study by Hsu et al. (67) found that monascin, a novel PPAR $\gamma$ agonist, could also activate $\mathrm{Nrf} 2$, and Li et al. (56) showed that luteoloside attenuated neuroinflammation in a focal cerebral ischemia model in rats by modulating the PPAR $\gamma / \mathrm{Nrf} 2 / \mathrm{NF}-\kappa \mathrm{B}$ signaling pathway.

\section{PPAR $y$ Downregulates the Expression of NLRP3}

The NLRP3 inflammasome is a multiprotein complex composed of NLRP3, apoptosis-associated speck-like protein containing a C-terminal caspase recruitment domain (ASC), and procaspase1. Recently, it was shown that thioredoxin-interacting protein (TXNIP) activation is a key event linking oxidative stress to inflammation and apoptosis in neurons (68). Mitochondria respond to oxidative stress induced by IR and ROS, prompting TXNIP to dissociate from the complex and rapidly bind to NLRP3 inflammasomes to induce their activation (69); this subsequently triggers the activation of caspase- 1 and the cleavage of pro-IL-1 $\beta$ and pro-IL-18, thereby inducing cell death and the release of many intracellular pro-inflammatory molecules (70). In addition, NF- $\mathrm{B}$ and mitogen-activated protein kinase (MAPK) signaling promotes NLRP3 inflammasome activation in neurons following ischemic stroke (71). Hong et al. (72) showed that MCC950, the specific inhibitor of NLRP3 reduced the neurological deficit score and improved the 28-day survival rate of CI/RI in diabetic mice.

In a recent study, PPAR $\gamma$ binding sites were found in the promoter regions of a member of the NLRP3 family, indicating a correlation between PPAR $\gamma$ activity and the NLRP3 family of proteins (69). It is reported that PPAR $\gamma$ is a negative regulator of NLRP3 inflammasome activation (73); for example, umbelliferone (UMB) may partially inhibit the activation of the TXNIP/NLRP3 inflammasome by activating $\operatorname{PPAR} \gamma$, thereby reducing the levels of IL- $1 \beta$, and IL-18 in brain tissue and reducing brain damage caused by focal ischemia (69). Similarly, the PPAR $\gamma$ agonist pioglitazone has been shown to ameliorate retinal ischemia/reperfusion injury by suppressing NLRP3 inflammasome activities (74).

\section{PPAR $\gamma$ Downregulates the Expression of HMGB1/RAGE}

HMGB1, a non-histone DNA-binding protein, has been identified as an important late pro-inflammatory mediator whose effect depends on the translocation of HMGB1 from the nucleus to the cytoplasm and its subsequent release into the extracellular space (75). HMGB1 localization is dependent upon the acetylation of lysine residues in its two nuclear localization signals (NLS1/2), and most non-acetylated HMGB1 is stored in the nucleus (76). Under CI/RI stimulation, hyperacetylation of the NLS sites on HMGB1 leads to the reduced affinity of HMGB1 for DNA, so HMGB1 is passively excreted by damaged and necrotic cells or is actively secreted by activated immune cells, leading to further immunological amplification $(11,76)$.

The receptor for advanced glycation end product (RAGE) is a transmembrane innate immune receptor, and the activation of this receptor plays an important role in mediating proinflammatory effects. Once HMGB1 is released from the cell into the extracellular space, it can bind to RAGE at the cell membrane, resulting in the activation of MAPK and NF- $\mathrm{B} / \mathrm{p} 53$ signaling pathways, which mediate the production of various downstream pro-inflammatory cytokines (11).

Le et al. (77) first found that glycyrrhizin (GLY), the specific inhibitor of HMGB1, reversed the hypoxia-ischemia insultinduced loss of neurons and myelin in the hippocampal region and neurobehavioral impairments, which was achieved through the inhibition of HMGB1 expression and nucleocytoplasmic translocation, the inflammatory response, the suppression of increases in microglia/astrocytes, and the inhibition of hippocampal cell apoptosis.

PPAR $\gamma$ is capable of suppressing HMGB1 acetylation; this reduces the secretion of HMGB1, thereby reducing brain damage caused by late inflammation in CI/RI (78). In models of OGD models of neuronal cells in vitro, a study showed that rosiglitazone downregulated the expression of RAGE by upregulating PPAR $\gamma$, and the secretion of HMGB1 decreased significantly, which could be reversed by administration of the PPAR $\gamma$ receptor inhibitor GW9662 (79). Pioglitazone has also been shown to mediate the downregulation of cytoplasmic translocation of HMGB1 and RAGE after IR, suggesting that this PPAR $\gamma$-dependent pathway may be involved in pioglitazone's inhibition of HMGB1/RAGE activation (11).

\section{PPAR $y$ Inhibits the NFAT Pathway}

NFAT is a family of transcription factors that is mainly expressed in immune cells and exists in the cytoplasm in an inactive phosphorylation state (59). Calcineurin $(\mathrm{CaN})$ is the serine/threonine protein phosphatase that is only regulated by calmodulin (CaM), which mainly catalyzes the dephosphorylation of phosphatidylserine and phosphatidylthreonine, and the main substrates, in vivo, are the NFAT family proteins (80).

CI/RI causes activation of NMDA receptors and other $\mathrm{Ca}^{2+}$ channels, as well as intracellular $\mathrm{Ca}^{2+}$ overload. Activated $\mathrm{Ca}^{2+}$ dependent $\mathrm{CaN}$ binds to the highly conserved sequence region of NFAT, leading to its dephosphorylation; following exposure to nuclear localization signals, it undergoes nuclear translocation, increasing the activity of the downstream pro-inflammatory factor IL-2 $(59,80)$.

Yang et al. (81) found that in T-cell-mediated inflammation, PPAR $\gamma$ exerts an anti-inflammatory effect by binding to ligands that can inhibit the expression of IL-2, either by inhibiting NFAT binding to its DNA target region and the subsequent transcription, or by inhibiting interactions between certain 
proteins. In addition, Raman et al. (82) showed that the PPAR $\gamma$ agonist 15d-PGJ2 reduced the translocation of NFAT into the nucleus, decreasing its activity, resulting in lower IL-2 expression; the addition of a PPAR $\gamma$ antagonist partially reversed these effect of 15d-PGJ2 on NFAT transcription.

\section{PPAR $y$ Inhibits the AP-1 Pathway}

AP-1 is an important nuclear transcription factor, as different combinations of Jun (c-Jun, junB, junD) and Fos [c-fos, fosB, fos-related antigen-1(fra-1)] family proteins determine the composition of active hetero/homodimers inside the cell and the activity of the genes that they regulate (59). The stimulation of external signals such as those induced by CI/RI can activate the transcription of immediate early genes c-Fos and c-Jun, and the later translation into nuclear proteins, such as those of the Fos and Jun families. Fos and Jun family proteins combine to form AP-1, which is a transcriptional regulatory protein. After retranslocating into the nucleus, AP-1 binds to the DNA regulatory region of the target gene, thus regulating its transcriptional efficiency and expression, in addition to playing a messenger role in the signaling cascades (83).

In inflammatory reactions, AP-1 can induce apoptosis and the synthesis of adhesion and inflammatory factors. Studies have shown that PPAR $\gamma$ inhibits the AP-1 signaling pathway to reduce the expression of inflammatory cytokines by competing with AP1 for binding to the coactivators p300 and CBP; thus it plays a neuroprotective role by inhibiting the infiltration and cytotoxic effects of inflammatory cells in CI/RI $(59,81)$. Oleic acid is an endogenous agonist of $\operatorname{PPAR} \gamma$, which can downregulate the expression of inflammatory factors in CI/RI, possibly due to the antagonistic effect of PPAR $\gamma$ on AP-1 signal transduction, which can be abolished by the PPAR $\gamma$ antagonist GW9662 (20).

In summary, PPAR $\gamma$ reduce CI/RI injury by inhibiting multiple inflammatory pathways and inflammatory cytokines, thus playing a neuroprotective role.

\section{THE ROLE OF PPAR $y$ IN INHIBITING MICROGLIAL ACTIVATION AND REGULATING THEIR PHENOTYPE DURING CI/RI}

Microglia are mononuclear phagocytes located in the CNS that, at physiological rest, monitor the microenvironment and clear apoptotic tissue. In the ischemic lesions induced by the MCAO model, microglia are rapidly activated and recruited from the peripheral region to the lesion site, and the number of microglia in the ischemic core increases and the cell body size and total branch length decrease (84). The change from "branchlike" to "shrub-like" and then to "amoeba-like," presenting a $\mathrm{CD} 11 \mathrm{~b}+$ branched amoeba-like morphology (84). Microglia may also polarize into multiple phenotypes. It is currently believed that microglia have at least two polarized states: type M1 and type M2 (85). M1-type activated microglia secrete proinflammatory cytokines, such as TNF- $\alpha$ and IL- $1 \beta$, contributing to the inflammatory response and leading to worse outcomes after cerebral ischemia. M2-type activated microglia generate
IL-10 and IL-4, transforming growth factor- $\beta$ (TGF- $\beta$ ), and certain cell repair factors, all of which drive the resolution of neuroinflammation and anti-inflammatory processes (86).

After CI/RI, microglia are activated by a variety of proinflammatory factors, chemokines, NO, and ROS, among others, and are converted into the M1 and M2 phenotypes, which try to maintain a balance between anti-inflammatory and proinflammatory states. However, M2-type microglia only exert anti-inflammatory effects in the early stage of ischemia, and gradually shift from M2-type to M1-type microglia in the middle stage, as microglia begin to shift from anti-inflammatory to pro-inflammatory responses (87). Moreover, some studies have shown that the number of activated microglia was positively correlated with the degree of CI/RI, and activated microglia trigger local inflammatory infiltration and injury of brain tissue (88). Therefore, inhibition of microglial activation and polarization is considered an effective strategy for the treatment of IR.

A large number of studies have shown that agonistinduced activation of PPAR $\gamma$ not only inhibits microglial activation, but also participates in the regulation of microglial phenotypes. Ionized calcium binding adaptor molecule 1 (Iba1) is a microglia/macrophage-specific protein antibody; relative to vehicle-treated MCAO model mice, those treated with the PPAR $\alpha / \gamma$ dual-agonist aleglitazar displayed a significant reduction in Ibal+ cells in the ischemic MCA territory, suggesting that aleglitazar reduces microglial activation (89). In adult rodents, pretreatment with rosiglitazone or pioglitazone 1 day prior to the induction of ischemia resulted in decreased microglial activation and macrophage infiltration, as well as decreased expression of pro-inflammatory mediators COX-2, iNOS, and IL-1 $\beta$ mRNA in the ischemic hemisphere (90). Recent studies indicate that PPAR $\gamma$ agonists attenuate ischemiainduced activation of microglia, expression of intracellular adhesion molecule 1 (ICAM-1), and neutrophil infiltration in C57BL/6 mice (91). The present results showed that tolllike receptor 4 (TLR4) was localized to CD11b/c-positive cells (microglia/macrophages) after CI/RI, and N15 treatment markedly reduced microglia/macrophage activation and TLR4 expression (19).

Studies have shown that XQ-1H, a novel derivative of ginkgolide $\mathrm{B}$, increased the expression of PPAR $\gamma$ in OGD reperfusion injury BV-2 cells (microglia); incubation with XQ$1 \mathrm{H}$ protected BV2 cells from OGD reperfusion injury, decreased the co-expression of CD16 (a marker for M1-type microglia) and Iba1, and increased the co-expression of CD206 (a marker for M2-type microglia) and Iba1. All these effects could be inhibited by administration of the PPAR $\gamma$ inhibitor GW9662. The results proved that $\mathrm{XQ}-1 \mathrm{H}$ regulated the polarization of microglia by promoting the anti-inflammatory phenotype and inhibiting the pro-inflammatory phenotype (21). White matter is composed mainly of axonal fibers, oligodendrocytes, and other glial cells, and is highly vulnerable to ischemic injury. White matter injury contributes to nearly half of the infarct volume seen following human ischemic stroke (30). It has been confirmed that rosiglitazone treatment improved white matter integrity in an in vivo CI/RI model, at least 
in part by promoting oligodendrogenesis and facilitating microglial polarization toward the beneficial, anti-inflammatory M2 phenotype (30). Furthermore, when M2 microglia were depleted from the mixed glial culture system, rosiglitazone was less effective in inducing oligodendrogenesis (30).

In conclusion, PPAR $\gamma$ can both inhibit microglial activation and promote microglial polarization toward a favorable M2 phenotype, thereby reducing inflammatory responses caused by microglial activation, and exert neuroprotective effects.

\section{THE ROLE OF PPAR $\gamma$ IN MAINTAINING THE BBB DURING CI/RI}

Neurovascular unit (NVU) is regarded as the basic structural and functional unit of brain, and BBB is a vital component of the neurovascular unit which is composed of tightly connected basement membranes of capillary endothelial cells, pericytes, and astrocyte endpoints (92). Numerous studies have confirmed that the important pathological processes occurring in the early stage of ischemia/reperfusion are accompanied by changes in BBB structure and function, which involved different factors including matrix metalloproteinases (MMPs), aquaporin (AQP), claudin, occludin, and inflammatory modulators (93). Pathophysiological changes occur in endothelial cells in the early stage of ischemia/reperfusion, which activate the in-born immune system and cause paracellular hyperpermeability in endothelial cells, and then recruitment of leucocytes causes endothelial barrier failure and activation of $\operatorname{MMP}(94,95)$. Activated MMPs cause disruption of TJs, which lead to increased paracellular permeability (96). Alongside, the stressed components of the NVU release a myriad of chemokines and cytokines (97). Activated microglia and an increased level of inflammatory molecules (IL-1 $\beta$ and TNF- $\alpha$ ) and ROS increase the number of adhesion receptors on endothelial cells permitting infiltration of leukocytesand other molecules which add to the BBB permeability precipitating vasogenic edema. These events ultimately can culminate into hemorrhagic transformation (HT) (96). Notably, the breakdown of BBB leads to brain influx of blood-derived vasculotoxic and neurotoxic macromolecules, causing reductions in capillary blood flow due to microvascular degeneration and pericapillary edema, depriving metabolically active neurons of oxygen, and other essential nutrients on the one hand and accumulating neurotoxins on the other hand, initiating neuronal functional and structural changes ultimately (98).

MMPs are a group of $\mathrm{Zn}$-containing proteases that can degrade all the components that make up the extracellular matrix (99). MMP-9 is an important member of the MMP family; it can degrade claudin-5 and other BBB components, and it participates in the pathological mechanisms involved in the destruction of the BBB, changing the vascular permeability and leading to the formation of vasogenic cerebral edema (100). Leukocytes, especially neutrophils, are the main source of MMP9 following brain ischemia (101). In CI/RI, NF- $\kappa$ B, and AP1 , which are involved in pro-inflammatory processes, bind to the transcriptional regulatory domain of MMP-9, promoting its gene transcription. In addition, in these processes, MMP-2, and
MMP-9 are activated and tissue inhibitor of metalloproteinase (TIMP-1, an MMP-9-specific inhibitor) is inhibited, resulting in an imbalance of pro-MMP/anti-MMP-related mechanisms; in contrast, a $30 \%$ reduction in infarct volume is observed following intravenous injection of TIMP-1 $(99,102)$. In addition, mifepristone, which acts as a PPAR $\gamma$ agonist, has been shown to attenuate $\mathrm{CI} / \mathrm{RI}$ by restoring the balance between MMPs and TIMPs and inhibiting inflammatory cytokines to maintain BBB homeostasis (103).

AQP4 is one of the most abundant molecules in the brain, and is a predominantly-expressed water channel molecule in astrocytic membranes at the $\mathrm{BBB}$ and brain-liquor interfaces. Beta-caryophyllene inhibits the expression of AQP4 and increases the expression of claudin-5 and the occludin enzyme by activating PPAR $\gamma$, thereby reducing BBB damage and edema in CI/RI (93).

As a proinflammatory cytokine, NLRP3 contributed to the regulation of MMP2/-9 and tight-junction protein expressions and endothelial cell permeability (104). Yang et al. (104) further showed that the contribution of NLRP3 to neurovascular damage was associated with an autocrine/paracrine pattern of NLRP3mediated IL-1ßrelease. Wang et al. (105) found that MCC950, the inhibitor of NLRP3, suppressed the expression of AQP4 and endothelin-1(ET-1) to reduce the accumulation of water and alleviate cerebral edema, suggesting that NLRP3 may be a potential molecular target for reducing neurovascular damage.

HMGB1 can trigger downstream inflammatory responses in $\mathrm{CI} / \mathrm{RI}$ model. In the process, HMGB1 triggers three specific downstream receptors, RAGE, TLR-2 and TLR-4 (106), which further induce the expression of NF- $\mathrm{B}, \mathrm{MMP}$, and MAPK (107, 108). The inflammatory cascade is involved in BBB disruption, apoptosis and nerve damage, and further aggravating brain damage. Anti-HMGB1 antibody can inhibit the morphological and functional changes in the BBB induced by HMGB1 (106). Telmisartan significantly decreased the number of Iba1-positive cells expressing HMGB1 and decreased plasma HMGB1 levels in PPAR $\gamma$-dependent manner, thus improving BBB damage (109).

In addition to affecting the above key cytokines and proteases, PPAR $\gamma$ also protects the BBB by inhibiting the Ras homolog A (RhoA)/Rho-associated kinase (ROCK) signaling pathway. RhoA is a member of the Ras superfamily of GTP-coupled proteins, and ROCK is a downstream serine/threonine kinase of RhoA. Cerebral ischemia activates tyrosine kinase (TK) and G proteincoupled receptors (GPCRs). Activated TK and GPCRs further activate RhoA, which then acts on the Rho-binding domain in the ROCK intermediate coiled-coil region to remove the inhibition maintained by the carboxyl-terminal $\mathrm{PH}$ structural region, ultimately activating ROCK (110). Activated ROCK causes damage to the BBB by phosphorylating the myosin light chain (MLC), which opens up the intercellular tight junction and increases endothelial intercellular permeability. Thus, the RhoA/ROCK signaling pathway exerts a regulatory effect on vascular endothelial function, and BBB permeability in CI/RI can be regulated by intervening in this pathway's altered signaling (110, 111). Studies have shown that after MCAO, PPAR $\gamma$ activated by pioglitazone resulted in decreased activity of RhoA and ROCK, decreased expression of MMP-9 and MDA, increased 
expression of the vascular endothelial tight junctions, occludin, SOD, and GSH-Px, and, finally, decreased infarct volume and maintenance of BBB integrity in rat brain tissue (110).

In short, NVU is a structural and functional whole. The multifactorial pathophysiology of CI/RI involving several components such as neurons, astrocytes, and endothelial cells which continually interact with each other has made CI/RI research very difficult. A lot of clinical and laboratory data show that protect the $\mathrm{BBB}$ after cerebral ischemia should be a priority for preclinical ischemic stroke investigations. And PPAR $\gamma$ can play a role in multiple regulation of $\mathrm{BBB}$, thereby playing a protective role.

\section{THE ROLE OF PPAR $\gamma$ IN PROMOTING ANGIOGENESIS AND NEUROGENESIS DURING CI/RI}

\section{Protective and Regenerative Effects of PPAR $\gamma$ on Blood Vessels}

Damage to cerebrovascular endothelial cells, the main structural components of the $\mathrm{BBB}$, results in the production of a variety of pro-inflammatory factors in the ischemic brain, which further exacerbate ischemic brain damage (112). Baculoviral inhibitor of apoptosis (IAP) repeat-containing 5 (BIRC5; also known as survivin) belongs to the IAP gene family and has recently been found to play a protective role in cerebrovascular endothelial cell injury. OGD experiments in mouse cerebral microvascular endothelial cells (bEnd.3) have shown that OGD-treated cells transfected with the PPAR $\gamma$ overexpression plasmid stimulated the proliferation of bEnd. 3 cells and reduced their apoptosis. In addition, results from electrophoretic mobility shift/supershift and chromatin immunoprecipitation assays suggested that PPAR $\gamma$ can bind to the promoter of BIRC5, and PPAR $\gamma$ can increase the expression of BIRC5 at the mRNA and protein levels, proving that PPAR $\gamma$ may protect the cerebral microvascular endothelium against IR injury by enhancing the activity of BIRC5 (113). VEGF is a highly specific vascular endothelial cell growth factor that can promote increased vascular permeability, the denaturation of extracellular matrix proteins, the migration and proliferation of vascular endothelial cells, and the formation of blood vessels. PPAR $\gamma$ activation also increases VEGF expression in vascular smooth muscle cells (114). PPAR $\gamma$ coactivator $1 \alpha$ (PGC-1 $\alpha$ ), a transcriptional coactivator, is a known regulator of VEGF gene transcription (115). It is reported that a significant upregulation of KDR (VEGF receptor-2) in the ischemic hemisphere of mice is induced by treatment with the $\operatorname{PPAR} \alpha / \gamma$ dual agonist aleglitazar, which promotes angiogenesis after MCAO (89).

\section{Effects of PPAR $\gamma$ on Neurogenesis and Cell Differentiation}

There have been descriptions of PPAR $\gamma$ 's involvement in pathways that are also involved in the control of the proliferation, migration, and differentiation of neural stem cells (116). The subventricular zone (SVZ), located in the lateral wall lining the lateral ventricle, harbors the largest population of neural stem cells capable of generating new neurons, astrocytes, and oligodendrocytes (12). In the ischemic model, the agonist pioglitazone activates $\operatorname{PPAR} \gamma$, which augments the proliferation of resident stem cells in the SVZ and the recruitment of mesenchymal stem cells in bone tissue; PPAR $\gamma$ is involved in the enhanced migration of both types of stem cells from the SVZ to the peri-infarct area, where they differentiate into mature neurons, glia, and blood vessels in association with activated protein kinase B (Akt), microtubule-associated protein 2 (MAP2), and VEGF (12). Oligodendrocytes are mainly involved in the formation of myelin sheaths and are highly sensitive to ischemic injury. In a CI/RI model, injured mature oligodendrocytes no longer produce functional myelin; since mature oligodendrocytes are not proliferative, successful regeneration of oligodendrocytes is essential for remyelination after brain injury. According to reports, rosiglitazone not only enhanced the proliferation of OPCs, but also promoted OPC differentiation into mature myelinating oligodendrocytes (30).

In addition, neurotrophic factors regulate the survival, proliferation, and differentiation of cells in the CNS (12, 117). PEDF has been established as a neuroprotective factor that promotes the survival of various types of neurons by increasing their resistance to neurotoxic damage, especially that induced by ischemic stroke (118). Experiments have shown that PPAR $\gamma$ mediates the function of PEDF in regulating survival, proliferation, and differentiation of cells in the CNS (118). In the MCAO rat model, the PPAR $\gamma$ agonist G-Rg1 significantly upregulates the expression of TGF- $\beta 1$ and brainderived neurotrophic factor (BDNF) in the hippocampal CA1 region, increases the expression of VEGF, nerve growth factor, and $\mathrm{Bcl}-2$, and enhances the formation of new synapses (4).

In summary, PPAR $\gamma$ promotes proliferation and differentiation of neural stem cells and proliferation of vascular endothelial cells, increases expression of neurotrophic factors and VEGF, and thus promotes neurogenesis and angiogenesis.

\section{ANTI-APOPTOTIC EFFECT OF PPAR $\gamma$ IN CEREBRAL CI/RI}

In CI/RI, PPAR $\gamma$ plays a complex multi-mechanistic neuroprotective role involving modulation of many processes, including inhibiting inflammation, reducing the level of oxidative stress, reducing the production of pro-apoptotic factors, and promoting the expression of anti-apoptotic factors. After IR, the production of ROS increases, leading to damage to intracellular biofilm lipids (for example, MDA), proteins and nucleic acids, mitochondrial damage, and the evoked release of apoptosis inducing factor (AIF) and cytochrome C (Cyt-C) in mitochondria (4). These upregulated levels of AIF and Cyt- $\mathrm{C}$ induce the activation of a downstream apoptotic cascade that includes the activation of cleaved caspase- 3 and cleaved caspase-9, both of which regulate the levels of anti-apoptotic proteins $(4,119,120)$. The activation of PPAR $\gamma$ during ischemic injury can dependently inhibit the NF-кB signaling pathway, known as the PPAR $\gamma$-ERK-NF- $\mathrm{B}$ signaling pathway, to reduce the secretion of iNOS, gelatinase $\mathrm{B}$, and scavenger receptor $\mathrm{A}$, 
thereby inhibiting the expression of the pro-apoptotic protein caspase- 3 and promoting the expression of the anti-apoptotic protein $\mathrm{Bcl}-2$, which can play a protective role in the nervous system (121). PPAR $\gamma$ reduces the synthesis of IFN- $\gamma$ and iNOS by inhibiting the JAK-STAT pathway, thereby regulating apoptosis (121). PPAR $\gamma$ can also prevent IR-induced neuronal apoptosis by upregulating the response element heme oxygenase-1 (HO-1), which has cytoprotective properties, and its anti-apoptotic effects may be based, in part, on its inhibition of inflammatory factors and its antioxidative function (122).

In in vivo MCAO and OGD models, the PPAR $\gamma$ agonist pioglitazone could effectively antagonize the neuronal pyroptosis caused by ischemia and hypoxia by inhibiting pyroptosis-related proteins such as caspase-1, the NLRP3 inflammasome, and ASC, and by reducing the release of cytokines such as IL- $1 \beta$ and IL18 (11). Ou et al. detected PPAR $\gamma$-positive cells on the ischemic side of the middle cerebral artery and found that treatment with the natural agonist 15d-PGJ2 reduced infarct size, the expression of caspase-3, the necrotic cascade response, and apoptosis (6, 123). In addition, dual-specificity phosphatase (DUSPs) acts specifically on JNK and p38, and studies have shown that the PPAR $\gamma$ agonist rosiglitazone induces phosphorylation of p38 and JNK MAPK in neurons, and inhibits neuronal apoptosis in an animal model of cerebral ischemia, which was mainly achieved by promoting the upregulation of DUSP8 and Bcl-xl (79).

Poly ADP-ribose polymerase-1 (PARP-1) is a protease ubiquitously expressed in eukaryotic cells that plays a key role in sensing and regulating cellular stress and repairing damage. Activation of PARP-1 promotes DNA repair and maintains genomic stability when DNA damage occurs, and the failure to repair DNA damage may trigger apoptosis and activation of caspase signaling. In the above process, PARP-1, as a substrate of caspases, is considered to be one of the markers of apoptotic initiation. Following excessive PARP-1 activation induced by the free radicals that are produced during cerebral IR, AIF, as a promoter of cell death, is released into the cytoplasm and then enters the nucleus to induce chromatin aggregation and DNA fragmentation, ultimately inducing PART-1-dependent cell death (124). Therefore, inhibition of PARP-1 activation has a neuroprotective effect. Jui-Sheng $\mathrm{Wu}$ and other studies have shown that in the OGD model, the analysis of the proapoptotic markers found greatly enhanced levels of caspase-3 and PARP1 proteins, which were relieved by PPAR $\gamma$ agonist 15d-PGJ2, which could be reversed by administration of the PPAR receptor inhibitor GW9662 (41).

In summary, PPAR $\gamma$ reduces the Parthanatos process and the apoptotic cascade by promoting DUSP8 upregulation, inhibiting the PARP-1 overactivation and the expression of caspase-3, and thereby plays a neuroprotective role in CI/RI.

\section{DISCUSSION}

$\mathrm{CI} / \mathrm{RI}$ is a complex pathological process. The damage and cascade of reactions caused by $\mathrm{CI} / \mathrm{RI}$ are related to oxidative stress, inflammation, cytokine-mediated damage, glutamate excitotoxicity, intracellular calcium overload, and many other factors. These factors interact with each other, ultimately leading to apoptosis or neuronal necrosis in the ischemic region. However, there is currently no effective treatment for ischemic brain injury. So far, intensive study of PPAR $\gamma$ has concentrated on its regulatory role in inflammation, atherosclerosis, insulin resistance, glucose metabolism, obesity, and tumor formation.

CI/RI markedly induced PPAR $\gamma$ nuclear translocation and the up-regulation of protein level, which relocalization suggested the activation of PPAR $\gamma$ (125). Xu et al. (126) found that after 60 min of ischemia, a time-dependent enhancement in PPAR $\gamma$ translocation was demonstrated by the analysis of cytosol and nuclear level of PPAR $\gamma$ at 2, 4, 8, and $24 \mathrm{~h}$ of reperfusion. It was worthy of note that this nuclear translocation of PPAR $\gamma$ occurred as early as $2 \mathrm{~h}$ of reperfusion, at which time point no detectable increase in total PPAR $\gamma$ expression was observed, implying that the onset of translocation was earlier than that of the up-regulation of protein expression, indicating that nuclear translocation of PPAR $\gamma$ was a quick response to I/R (126).

At present, the mechanism of CI/RI is still not completely understood, and the PPAR $\gamma$ pathway is intricate. Our review shows that PPAR $\gamma$ plays a potentially protective role against $\mathrm{CI} / \mathrm{RI}$ through its interaction with multiple pathways and its multi-targeted effects. Many studies have shown that PPAR $\gamma$ agonistic ligands such as 15d-PGJ2, pioglitazone, troglitazone, and rosiglitazone exerted their neuroprotective effects by promoting the activation and expression of PPAR $\gamma$, and by enhancing its anti-inflammatory effects, reducing the levels of oxidative stress and ER stress, increasing the expression of antioxidants, maintaining BBB integrity, inhibiting the activation of microglia and regulating their phenotype, and promoting nerve regeneration, angiogenesis, and reducing apoptosis. However, animal and cell models are often used in the related study of the neuroprotective effect of PPAR $\gamma$ in CI/RI, and there is a lack of large-scale clinical research at present. Therefore, with the development of molecular biology, bioinformatics, and other related subjects, we can more thoroughly and precisely explore the activation state and the independent mechanisms of PPAR $\gamma$ to develop more effective PPAR $\gamma$ agonists, and to find the most effective target for the treatment of CI/RI injury. Ultimately, the study of PPAR $\gamma$ is expected to provide a new therapeutic approach for the treatment of ischemic cerebrovascular diseases, and it is important for the prevention of neurodegenerative diseases such as Parkinson's disease, Alzheimer's disease, and Huntington's disease.

\section{AUTHOR CONTRIBUTIONS}

JK, YD, and BS devised the review. JK and YD conducted literature review and provided the first draft. JK, SL, and YX created the figures. All authors contributed to manuscript revision and approved the submitted version.

\section{FUNDING}

This work was funded by National Natural Science Foundation (No. 31760271). 


\section{REFERENCES}

1. Eltzschig $\mathrm{H}$, Eckle $\mathrm{T}$. Ischemia and reperfusion-from mechanism to translation. Nat Med. (2011) 17:1391-401. doi: 10.1038/nm.2507

2. Zhang T, Ge JJ. Research progress on the protective effect of peroxisome proliferator-activated receptors on the inflammatory response caused by tissue ischemia/reperfusion injury. Anhui Med Pharm. (2012) 16:16946. doi: 10.1016/j.pneurobio.2017.10.002

3. Zhong L, Ding L, He W, Tian X, Cao H, Song Y, et al. Systolic hypertension related single nucleotide polymorphism is associated with susceptibility of ischemic stroke. Eur Rev Med Pharmacol. (2017) 21:2901-6.

4. Xie W, Zhou P, Sun Y, Meng X, Dai Z, Sun G, et al. Protective effects and target network analysis of Ginsenoside $\mathrm{Rgl}$ in cerebral ischemia and reperfusion injury: a comprehensive overview of experimental studies. Cells. (2018) 7:270. doi: 10.3390/cells7120270

5. Sun J, Liu KY. Research progress on the protective effect of PPAR $\gamma$ agonists on cerebral ischemia-reperfusion injury. Chin J Pract Nerv Dis. (2011) 14:91-3.

6. Yu Z, Liu KY, Liao XM. Research progress on the protective effect of PPAR $\gamma$ in ischemic cerebrovascular disease. Tianjin Med J. (2012) 40:1174-6. doi: 10.3969/j.issn.0253-9896.2012.11.031

7. Villapol S. Roles of peroxisome proliferator-activated receptor gamma on brain and peripheral inflammation. Cell Mol Neurobiol. (2018) 38:12132. doi: 10.1007/s10571-017-0554-5

8. Deng YB, Tang WY. Research progress on neuroprotective effects of PPAR $\gamma$. Chin J Neuro surg Dis Res. (2010) 9:92-4.

9. Liu CH, Lee T, Lin YS, Sung PS, Wei YC, Li YR. Pioglitazone and PPAR- $\gamma$ modulating treatment in hypertensive and type 2 diabetic patients after ischemic stroke: a national cohort study. Cardiovasc Diabetol. (2020) 19:2. doi: 10.1186/s12933-019-0979-x

10. Shehata A, Ahmed A, Abdelrehim A, Heeba G. The impact of single and combined PPAR- $\alpha$ and PPAR- $\gamma$ activation on the neurological outcomes following cerebral ischemia reperfusion. Life Sci. (2020) 252:117679. doi: 10.1016/j.lfs.2020.117679

11. Xia PP, Pan YD, Zhang F, Wang N, Wang E, Guo QL, et al. Pioglitazone confers neuroprotection against ischemia-induced pyroptosis due to its inhibitory effects on HMGB-1/RAGE and Rac1/ROS pathway by activating PPAR- $\gamma$. Cell Physiol Biochem. (2018) 45:2351-68. doi: 10.1159/000488183

12. Kinouchi T, Kitazato K, Shimada K, Yagi K, Tada Y, Matsushita N, et al. Correction to: treatment with the PPAR $\gamma$ agonist pioglitazone in the early post-ischemia phase inhibits pro-inflammatory responses and promotes neurogenesis via the activation of innateand bone marrow-derived stem cells in rats. Transl Stroke Res. (2018) 9:317. doi: 10.1007/s12975-017-0589-4

13. Hang Y, Peng t, Chen C, Xia PP, Zhang F, Li LY, et al. Effects of PPAR- $\gamma$ activation on inflammation in cerebral ischemia and reperfusion injury. $J$ Clin Anesthesiol. (2020) 7:685-690.

14. Liu HY, Feng ZR, Sun H, Meng AG, Zhao JJ, Zhang WT. The relationship between PPAR gamma activation and pyroptosis in the early stage of cerebral ischemia-reperfusion in rats. Tianjin Med J. (2020) 1:34-7.

15. Li Y, Zhu ZY, Lu BW, Huang TT, Zhang YM, Zhou NY, et al. Rosiglitazone ameliorates tissue plasminogen activator-induced brain hemorrhage after stroke. CNS Neurosci Ther. (2019) 12:1343-52. doi: 10.1111/cns.13260

16. Wang Li, Zhang MJ, Li WJ, Mao SL, Liu ML, Huang S, et al. Rosiglitazone protect PC12 cells against oxygen-glucose deprivation/reoxygenation through HMGB1 reduction and DUSP8 upregulation. J Stroke and Neuro Dis. (2019) 6:541-5.

17. Mu Q. Effect of Activated PPAR on Phagocytosis of Microglia Cells and Expression of CD36 in Rat Brain Tissue Around ICH. Suzhou: Suzhou University (2018)

18. Li Y, Ren T, Xu L, Wang Y, Yang BY, Luo HH, et al. Propane-2-sulfonic acid octadec-9-enyl-amide, a novel peroxisome proliferator-activated receptors $\alpha$ and $\gamma$ dual agonist, enhances hippocampal neurogenesis and neuroplasticity in rats with cerebral ischaemia. Neuroreport. (2019) 30:1299306. doi: 10.1097/WNR.0000000000001360

19. Li Y, Xu L, Zeng KY, Xu ZT, Suo DQ, Peng L, et al. Propane2-sulfonic acid octadec-9-enyl-amide, a novel PPAR $\alpha / \gamma$ dual agonist,protects against ischemia-induced brain damage in mice by inhibiting inflammatory responses. Brain Behav Immun. (2017) 66:289-301. doi: 10.1016/j.bbi.2017.07.015

20. Song J, Kim Y, Lee D, Lee S, Park H, Lee D, et al. Neuroprotective effects of oleic acid in rodent models of cerebral ischaemia. Sci Rep. (2019) 9:10732. doi: 10.1038/s41598-019-47057-z

21. Liu R, Diao JJ, He SC, Li BB, Fei YX, Li YM, et al. XQ-1H protects against ischemic stroke by regulating microglia polarization through PPAR $\gamma$ pathway in mice. Int Immunopharmacol. (2018) 57:7281. doi: 10.1016/j.intimp.2018.02.014

22. Gao Y, Li W, Liu YL, Wang Y, Zhang JC, Li M, et al. Effect of telmisartan on preventing learning and memory deficits via peroxisome proliferator-activated receptor- $\gamma$ in vascular dementia spontaneously hypertensive rats. J Stroke Cerebrovasc Dis. (2018) 27:277-85. doi: 10.1016/j.jstrokecerebrovasdis.2017.01.025

23. Li Y, Guan Y, Wang Y, Yu CL, Zhai FG, Guan LX. Neuroprotective effect of the ginsenoside $\mathrm{Rg} 1$ on cerebral ischemic injury in vivo and in vitro is mediated by PPAR-regulated antioxidative and anti-inflammatory pathways. Evid-Based Compl Alt. (2017) 2017:7842082. doi: 10.1155/2017/7842082

24. Wang HJ, Wang YJ, Li RQ, Zhang JW. Effects of 15-hydroxyeicosatetraenoic acid on SOD and MDA in brain tissue of rats with cerebral ischemiareperfusion injury. J Qiqihar Med University. (2019) 40:2377-9. doi: 10.3969/j.issn.1002-1256.2019.19.001

25. He Q. Protective Effects of Liraglutide on Focal Cerebral Ischemic Injury with Diabetes Mellitus Rat by Activating PPARs. Zunyi: Zunyi Medical University (2017).

26. Huang LH, Li G, Feng XF, Wang LJ, Du XH. Effects of 15d-PGJ2 on activation of microglia and neuronal apoptosis in diabetic rats with cerebral ischemia-reperfusion injury. Stroke Neuro Dis. (2016) 23:149-53. doi: 10.3969/j.issn.1007-0478.2016.03.001

27. Wang FC, Yuan SJ, Feng H. The role of peroxisome proliferator-activated receptor $\gamma$ and its ligand in cerebral hypoxic-ischemic diseases. J Int Neurol Neurosurg. (2009) 36:507-10. doi: 10.16636/j.cnki.jinn.2009.06.008

28. Bonfoco E, Krainc D, Ankarcrona M, Nicotera P, Lipton S. Apoptosis and necrosis: two distinct events induced, respectively, by mild and intense insults with $\mathrm{N}$-methyl-D-aspartate or nitric oxide/superoxide in cortical cell cultures. Proc Natl Acad Sci USA. (1995) 92:71626. doi: 10.1073/pnas.92.16.7162

29. Romera C, Hurtado O, Mallolas J, Pereira M, Morales J, Romera A, et al. Ischemic preconditioning reveals that GLT1/EAAT2 glutamate transporter is a novel PPARgamma target gene involved in neuroprotection. J Cerebr Blood Flow Metab. (2007) 27:1327-38. doi: 10.1038/sj.jcbfm. 9600438

30. Han L, Cai W, Mao L, Liu J, Li P, Leak R, et al. Rosiglitazone promotes white matter integrity and long-term functional recovery after focal cerebral ischemia. Stroke. (2015) 46:2628-36. doi: 10.1161/STROKEAHA.115.0 10091

31. Zhu CH, Miao JY, Yang Y, Cui HY, Ji H, Zhang XJ. The intrinsic PEDF expression after focal cerebral ischemia in rats and the regulation of telmisartan. J Brain Nervous Dis. (2013) 21:49-52.

32. García-Bueno B, Caso J, Pérez-Nievas B, Lorenzo P, Leza J. Effects of peroxisome proliferator-activated receptor gamma agonists on brain glucose and glutamate transporters after stress in rats. Neuropsychopharmacol. (2007) 32:1251-60. doi: 10.1038/sj.npp.1301252

33. Gu ZW, Wang LM, Qiao WH. PPAR $\gamma$ and ischemia reperfusion injury. Chin Healthc Front. (2009) 4:23-5.

34. Cao SS. The Role of PPAR in Ischemic Preconditioning and Subsequent Ischemic Brain Injury. Tianjin: Tianjin Medical University (2018)

35. Pang YN. Berberine Confers Neuroprotective Against Cerebral Ischemic by Regulating PPAR $\gamma$ Expression. Beijing: Tsinghua University (2016).

36. Tschopp J. Mitochondria: Sovereign of inflammation? Eur J Immuno. (2011) 41:1196-202. doi: 10.1002/eji.201141436

37. Murakami K, Kondo T, Kawase M, Li Y, Sato S, Chen S, et al. Mitochondrial susceptibility to oxidative stress exacerbates cerebral infarction that follows permanent focal cerebral ischemia in mutant mice with manganese superoxide dismutase deficiency. J Neurosci. (1998) 18:20513. doi: 10.1523/JNEUROSCI.18-01-00205.1998

38. Schieffer B, Luchtefeld M, Braun S, Hilfiker A, Hilfiker-Kleiner D, Drexler $\mathrm{H}$. Role of $\mathrm{NAD}(\mathrm{P}) \mathrm{H}$ oxidase in angiotensin II-induced 
JAK/STAT signaling and cytokine induction. Circ Res. (2000) 87:1195-201. doi: 10.1161/01.RES.87.12.1195

39. Ushio-Fukai M, Tang Y, Fukai T, Dikalov S, Ma Y, Fujimoto M, et al. Novel role of gp91(phox)-containing $\mathrm{NAD}(\mathrm{P}) \mathrm{H}$ oxidase in vascular endothelial growth factor-induced signaling and angiogenesis. Circ Res. (2002) 91:11607. doi: 10.1161/01.RES.0000046227.65158.F8

40. Cadenas E, Davies K. Mitochondrial free radical generation, oxidative stress, and aging. Free Radic Biol Med. (2000) 29:222-30. doi: 10.1016/S0891-5849(00)00317-8

41. Wu J, Tsai $\mathrm{H}$, Cheung $\mathrm{W}$, Hsu C, Lin T. PPAR $\gamma$ ameliorates neuronal apoptosis and ischemic brain injury via suppressing NF-kB-driven p22phox transcription. Mol Neurobiol. (2016) 53:3626-45. doi: 10.1007/s12035-015-9294-z

42. Raz L, Zhang Q, Zhou C, Han D, Gulati P, Yang L, et al. Role of Rac1 GTPase in NADPH oxidase activation and cognitive impairment following cerebral ischemia in the rat. PLoS ONE. (2010) 5:e12606. doi: 10.1371/journal.pone.0012606

43. Chen ZZ, Cui QH, Yang JC. Protective effect and mechanism of PPAR $\gamma$ in organ ischemia-reperfusion injury. Prog Physiol Sci. (2017) 48:63-8.

44. Kapadia R, Yi J, Vemuganti R. Mechanisms of anti-inflammatory and neuroprotective actions of PPAR-gamma agonists. Front Biosci. (2008) 13:1813-26. doi: 10.2741/2802

45. Hwang J, Kleinhenz D, Lassègue $B$, Griendling $K$, Dikalov $S$, Hart C. Peroxisome proliferator-activated receptor-gamma ligands regulate endothelial membrane superoxide production. Am J Physiol Cell Physiol. (2005) 288:C899-905. doi: 10.1152/ajpcell.00474.2004

46. Collino M, Aragno M, Mastrocola R, Gallicchio M, Rosa A, Dianzani $\mathrm{C}$, et al. Modulation of the oxidative stress and inflammatory response by PPAR-gamma agonists in the hippocampus of rats exposed to cerebral ischemia/reperfusion. Eur J Pharmacol. (2006) 530:70-80. doi: 10.1016/j.ejphar.2005.11.049

47. Zeng Y, Xie K, Dong H, Zhang H, Wang F, Li Y, et al. Hyperbaric oxygen preconditioning protects cortical neurons against oxygen-glucose deprivation injury: role of peroxisome proliferator-activated receptorgamma. Brain Res. (2012) 1452:140-50. doi: 10.1016/j.brainres.2012.02.063

48. Shimazu T, Inoue I, Araki N, Asano Y, Sawada M, Furuya D, et al. A peroxisome proliferator-activated receptor-gamma agonist reduces infarct size in transient but not in permanent ischemia. Stroke. (2005) 36:3539. doi: 10.1161/01.STR.0000152271.21943.a2

49. Park E, Park S, Joe E, Jou I. 15d-PGJ2 and rosiglitazone suppress Janus kinase-STAT inflammatory signaling through induction of suppressor of cytokine signaling 1 (SOCS1) and SOCS3 in glia. J Biol Chem. (2003) 278:14747-52. doi: 10.1074/jbc.M210819200

50. Oberkofler H, Klein K, Felder T, Krempler F, Patsch W. Role of peroxisome proliferator-activated receptor-gamma coactivator-1alpha in the transcriptional regulation of the human uncoupling protein 2 gene in INS-1E cells. Endocrinology. (2006) 147:966-76. doi: 10.1210/en.2005-0817

51. Fu X, Gao D. Endoplasmic reticulum proteins quality control and the unfolded protein response: the regulative mechanism of organisms against stress injuries. BioFactors. (2014) 40:569-85. doi: 10.1002/biof.1194

52. Li Y, Guo Y, Tang J, Jiang J, Chen Z. New insights into the roles of CHOP-induced apoptosis in ER stress. Acta Bioch Bioph Sin. (2015) 47:1467. doi: $10.1093 /$ abbs/gmu128

53. Chen Y, Liu S, Chen G. Aggravation of cerebral ischemia/reperfusion injury by peroxisome proliferator-activated receptor-gamma deficiency via endoplasmic reticulum stress. Med Sci Monitor. (2019) 25:751826. doi: 10.12659/MSM.915914

54. Shan B, Mogi M, Iwanami J, Bai H, Kan-No H, Higaki A, et al. Attenuation of stroke damage by angiotensin II type 2 receptor stimulation via peroxisome proliferator-activated receptor-gamma activation. Hypertens Res. (2018) 41:839-48. doi: 10.1038/s41440-018-0082-9

55. Kim J, Song J, Park K. The multifaceted factor peroxisome proliferatoractivated receptor $\gamma(\operatorname{PPAR} \gamma)$ in metabolism, immunity, and cancer. Arch Pharm Res. (2015) 38:302-12. doi: 10.1007/s12272-015-0559-x

56. Li Q, Tian Z, Wang M, Kou J, Wang C, Rong X, et al. Luteoloside attenuates neuroinflammation in focal cerebral ischemia in rats via regulation of the PPAR $\gamma / \mathrm{Nrf} 2 / \mathrm{NF}-\mathrm{kB}$ signaling pathway. Int Immunopharmacol. (2019) 66:309-16. doi: 10.1016/j.intimp.2018.11.044
57. Han DX, Zhang Y, Lin XM, Liu Z. Study on JAK/STAT pathway and electroacupuncture-intervention on apoptosis after focal cerebral ischemia and reperfusion. Chin J Tradit Chin Med Pharm. (2013) 28:1839-41.

58. Yang ZH, Hu Y, Sun XB. Research progress of JAK/STAT signal transduction pathway and traditional Chinese medicine intervention in ischemic stroke. Chin Pharmacol Bull. (2016) 32:889-94.

59. Chen YX, Wang WM, Zhou T, Chen N. The role of PPAR- $\gamma$ and related signal transduction pathways. Chinese J Cell Biol. (2006) 28:382-6.

60. Candelario-Jalil E, Fiebich B. Cyclooxygenase inhibition in ischemic brain injury. Curr Pharm Design. (2008) 14:140118. doi: $10.2174 / 138161208784480216$

61. Zhu XD, Yu ZJ, Sun BF, Yu Y, Li YM, LUO SP, et al. The effect of NF.KB signaling pathway on apoptosis in cerebral ischemia reperfusion injury in mic. J Apoplexy Nerv Dis. (2016) 33:484-8.

62. Rossi A, Kapahi P, Natoli G, Takahashi T, Chen Y, Karin M, et al. Anti-inflammatory cyclopentenone prostaglandins are direct inhibitors of IkappaB kinase. Nature. (2000) 403:103-8. doi: 10.1038/47520

63. Pedruzzi L, Stockler-Pinto M, Leite M, Mafra D. Nrf2-keap1 system versus NF- $\mathrm{BB}$ : the good and the evil in chronic kidney disease? Biochimie. (2012) 94:2461-6. doi: 10.1016/j.biochi.2012.07.015

64. Duan SN, Wang GQ, Li T, Dong L,Wu CM. Research progress of PPAR $\gamma$ and Nrf2 in endogenous hematoma scavenging after intracerebral hemorrhage. World Latest Med Inform. (2018) 18:76-7. doi: 10.19613/j.cnki.1671-3141.2018.55.032

65. Xu XJ. Explore the Function of Nrf2/ARE Pathway on NLRP3 Inflammasome and the Relevant Mechanism during Cerebral Ischemia-Reperfusion. Zhenjiang: Jiangsu University (2018).

66. Huang X, Qiu Y, Wang B, Ding H, Tang Y, Zeng R, et al. Effects of Astragaloside IV combined with the active components of Panax notoginseng on oxidative stress injury and nuclear factorerythroid 2-related factor $2 /$ heme oxygenase-1 signaling pathway after cerebral ischemia-reperfusion in mice. Pharmacogn Mag. (2014) 10:402-9. doi: 10.4103/0973-1296.141765

67. Hsu W, Lee B, Pan T. Monascin attenuates oxidative stress-mediated lung inflammation via peroxisome proliferator-activated receptorgamma (PPAR $\gamma)$ and nuclear factor-erythroid 2 related factor 2 (Nrf-2) modulation. J Agr Food Chem. (2014) 62:5337-44. doi: 10.1021/jf50 $1373 a$

68. Zhou R, Tardivel A, Thorens B, Choi I, Tschopp J. Thioredoxin-interacting protein links oxidative stress to inflammasome activation. Nat Immunol. (2010) 11:136-40. doi: 10.1038/ni.1831

69. Wang X, Li R, Wang X, Fu Q, Ma S. Umbelliferone ameliorates cerebral ischemia-reperfusion injury via upregulating the PPAR gamma expression and suppressing TXNIP/NLRP3 inflammasome. Neurosci Lett. (2015) 600:182-7. doi: 10.1016/j.neulet.2015.06.016

70. Fann D, Lee S, Manzanero S, Chunduri P, Sobey C, Arumugam T. Pathogenesis of acute stroke and the role of inflammasomes. Ageing Res Rev. (2013) 12:941-66. doi: 10.1016/j.arr.2013.09.004

71. Fann D, Lim Y, Cheng Y, Lok K, Chunduri P, Baik S, et al. Evidence that NF- $\mathrm{KB}$ and MAPK signaling promotes NLRP inflammasome activation in neurons following ischemic stroke. Mol Neurobiol. (2018) 55:108296. doi: 10.1007/s12035-017-0394-9

72. Hong P, Li Feng X, Gu RN, Fang YY, Lai LY, Wang YW, et al. Inhibition of NLRP3 inflammasome ameliorates cerebral ischemia-reperfusion injury in diabetic mice. Neural Plast. (2018) 2018:9163521. doi: 10.1155/2018/91 63521

73. Meng Q, Feng Z, Zhang X, Hu L, Wang M, Zhang H, et al. PPAR $\gamma$ activation exerts an anti-inflammatory effect by suppressing the NLRP3 inflammasome in spinal cord-derived neurons. Mediat Inflamm. (2019) 2019:6386729. doi: 10.1155/2019/6386729

74. Zhang Y, Wang R, Li W, Xia F, Liu L. Pioglitazone ameliorates retinal ischemia/reperfusion injury suppressing NLRP3 inflammasome activities. Int J Ophthalmol-Chi. (2017) 10:1812-8. doi: 10.18240/ijo.2017. 12.04

75. Kalyan S, Chow A. Staphylococcal toxic shock syndrome toxin-1 induces the translocation and secretion of high mobility group-1 protein from both activated $\mathrm{T}$ cells and monocytes. Mediat Inflamm. (2008) 2008:512196. doi: $10.1155 / 2008 / 512196$ 
76. Ying S, Xiao X, Chen T, Lou J. PPAR ligands function as suppressors that target biological actions of HMGB1. PPAR Res. (2016) 2016:2612743. doi: 10.1155/2016/2612743

77. Le K, Wu SS, Chibaatar E, Ali A, Guo YJ. Alarmin HMGB1 plays a detrimental role in hippocampal dysfunction caused by hypoxiaischemia insult in neonatal mice: evidence from the application of the HMGB1 inhibitor glycyrrhizin. ACS Chem Neurosci. (2020) 11:97993. doi: 10.1021/acschemneuro.0c00084

78. Hwang J, Lee W, Kang E, Ham S, Yoo T, Paek K, et al. Ligandactivated peroxisome proliferator-activated receptor- $\delta$ and $-\gamma$ inhibit lipopolysaccharide-primed release of high mobility group box 1 through upregulation of SIRT1. Cell Death Dis. (2014) 5:e1432. doi: $10.1038 /$ cddis. 2014.406

79. Wang L, Zhang MJ, Li WJ, Mao SL, Liu ML, Huang S, et al. Rosiglitazone protect $\mathrm{PC} 12$ cells against oxygen-glucose deprivation/reoxygenation through HMGB1 reduction and DUSP8 upregulation. J Apoplexy Nerv Dis. (2019) 36:541-5

80. Shioda N, Moriguchi S, Shirasaki Y, Fukunaga K. Generation of constitutively active calcineurin by calpain contributes to delayed neuronal death following mouse brain ischemia. J Neurochem. (2006) 98:31020. doi: 10.1111/j.1471-4159.2006.03874.x

81. Yang $\mathrm{X}$, Wang $\mathrm{L}$, Chen $\mathrm{T}$, Hodge $\mathrm{D}$, Resau J, DaSilva L, et al. Activation of human T lymphocytes is inhibited by peroxisome proliferatoractivated receptor gamma (PPARgamma) agonists. PPARgamma coassociation with transcription factor NFAT. J Biol Chem. (2000) 275:45414. doi: 10.1074/jbc.275.7.4541

82. Raman P, Kaplan B, Thompson J, vanden Heuvel J, Kaminski N. 15Deoxy-delta12,14-prostaglandin J2-glycerol ester, a putative metabolite of 2-arachidonyl glycerol, activates peroxisome proliferator activated receptor gamma. Mol Pharmacol. (2011) 80:201-9. doi: 10.1124/mol.110.070441

83. Shen X, Cui GY, Zhang L, Liu YH, Ge W, Zhang ZS, et al. The activation of AP-1DNA binding activity in hippocampal CA1subfield of rats following global brain ischemia-reperfusion and the effects of RSM. Jiangsu Med J. (2004) 2004:422-24. doi: 10.19460/j.cnki.0253-3685.2004.06.011

84. Zhang $\mathrm{K}, \mathrm{Hu} \mathrm{LM}$, Wang SX. The role of microglia in the pathological progression of cerebral ischemia. Chin J Clin Pharmacol. (2020) 36:2517-20. doi: 10.13699/j.cnki.1001-6821.2020.16.037

85. Mi RL, Xue GF. The biphasic effect of microglia-mediated neuroinflammation in ischemic stroke. J Brain Nervous Dis. (2020) 28:591-4.

86. Orihuela R, McPherson C, Harry G. Microglial M1/M2 polarization and metabolic states. Br J Pharmacol. (2016) 173:649-65. doi: 10.1111/bph.13139

87. Qi YN, Guo DZ, Pan SY. The role of microglia cells in cerebral ischemia reperfusion injury. Chin Med Herald. (2019) 16:26-8.

88. Yuan XP, Jiang XJ, Li YY, Wang YX, Zeng M, Xiao X, et al. Research progress of microglia-mediated inflammatory response involved in cerebral ischemiareperfusion injury. Chin J Geriatr Heart Brain Vessel Dis. (2019) 21:1112-14. doi: 10.3969/j.issn.1009-0126.2019.10.028

89. Boujon V, Uhlemann R, Wegner S, Wright M, Laufs U, Endres M, et al. Dual PPAR $\alpha / \gamma$ agonist aleglitazar confers stroke protection in a model of mild focal brain ischemia in mice. J Mol Med. (2019) 97:112738. doi: 10.1007/s00109-019-01801-0

90. Luo Y, Yin W, Signore A, Zhang F, Hong Z, Wang S, et al. Neuroprotection against focal ischemic brain injury by the peroxisome proliferatoractivated receptor-gamma agonist rosiglitazone. J Neurochem. (2006) 97:435-8. doi: 10.1111/j.1471-4159.2006.03758.x

91. Tureyen K, Kapadia R, Bowen K, Satriotomo I, Liang J, Feinstein D, et al. Peroxisome proliferator-activated receptor-gamma agonists induce neuroprotection following transient focal ischemia in normotensive, normoglycemic as well as hypertensive and type-2 diabetic rodents. $J$ Neurochem. (2007) 101:41-56. doi: 10.1111/j.1471-4159.2006.04376.x

92. Xie ZY. Astrocytes, pericytes and blood-brain barrier. J Apoplexy Nervous Dis. (2007) 24:378-80.

93. Li RR. Effects of $\beta$-Caryophyllene on Focal Cerebal Ischemia Reperfusion Injury in rats and its Mechanism Study. Chongqing: Chongqing Medical University (2016).

94. Amantea D, Micieli G, Tassorelli C, Cuartero M, Ballesteros I, Certo M, et al. Rational modulation of the innate immune system for neuroprotection in ischemic stroke. Front Neurosci. (2015) 9:147. doi: 10.3389/fnins.2015.00147
95. Rodrigues S, Granger D. Role of blood cells in ischaemia-reperfusion induced endothelial barrier failure. Cardiovasc Res. (2010) 87:2919. doi: $10.1093 / \mathrm{cvr} / \mathrm{cvq} 090$

96. Sifat A, Vaidya B, Abbruscato T. Blood-brain barrier protection as a therapeutic strategy for acute ischemic stroke. AAPS J. (2017) 19:95772. doi: 10.1208/s12248-017-0091-7

97. Nag S, Kapadia A, Stewart D. Review: molecular pathogenesis of blood-brain barrier breakdown in acute brain injury. Neuropathol. Appl Neurobiol. (2011) 37:3-23. doi: 10.1111/j.1365-2990.2010.01138.x

98. Winkler E, Bell R, Zlokovic B. Central nervous system pericytes in health and disease. Nat Neurosci. (2011) 14:1398-405. doi: 10.1038/nn.2946

99. Liu ZJ, Tian ZH, Xue S, Jiao JS, Liu W. Protective effects of PPAR $\gamma$ agonist on the blood brain barrier (BBB) and Its mechanisms after cerebral ischemiareperfusion. China J Stroke. (2009) 4:360-4

100. Liu ZJ. The Study of the Relation bewteen PPAR $\gamma$ and Brain Ischemia Injury and its Protective Mechanisms. Changsha: Central South University (2006).

101. Gidday J, Gasche Y, Copin J, Shah A, Perez R, Shapiro S, et al. Leukocyte-derived matrix metalloproteinase- 9 mediates blood-brain barrier breakdown and is proinflammatory after transient focal cerebral ischemia. Am J Physiol Heart C. (2005) 289:H558-68. doi: 10.1152/ajpheart.012 75.2004

102. Chakraborti S, Mandal M, Das S, Mandal A, Chakraborti T. Regulation of matrix metalloproteinases: an overview. Mol Cell Biochem. (2003) 253:26985. doi: 10.1023/A:1026028303196

103. Wu X, Sun X, Wang S, Chen J, Bi Y, Jiang D. Mifepristone alleviates cerebral ischemia-reperfusion injury in rats by stimulating PPAR $\gamma$. Eur Rev Med Pharmaco. (2018) 22:5688-96. doi: 10.26355/eurrev_201809_15836

104. Yang F, Wang ZY, Wei XB, Han HR, Meng XF, Zhang Y, et al. NLRP3 deficiency ameliorates neurovascular damage in experimental ischemic stroke. J Cereb Blood Flow Metab. (2014) 34:660-7. doi: $10.1038 /$ jcbfm.2013.242

105. Wang HN, Chen HP, Jin J, Liu QQ, Zhong D, Li GZ. Inhibition of the NLRP3 inflammasome reduces brain edema and regulates the distribution of aquaporin-4 after cerebral ischaemia-reperfusion. Life Sci. (2020) 251:117638. doi: 10.1016/j.lfs.2020.117638

106. Mu SW, Dang Y, Wang SS, Gu JJ. The role of high mobility group box 1 protein in acute cerebrovascular diseases. Biomed Rep. (2018) 9:1917. doi: 10.3892/br.2018.1127

107. Fiuza C, Bustin M, Talwar S, Tropea M, Gerstenberger E, Shelhamer J, et al. Inflammation-promoting activity of HMGB1 on human microvascular endothelial cells. Blood. (2003) 101:2652-60. doi: 10.1182/blood-2002-05-1300

108. Xi Y, Shao F, Bai XY, Cai GY, Lv Y, Chen XM. Changes in the expression of the Toll-like receptor system in the aging rat kidneys. PLoS ONE. (2014) 9:e96351. doi: 10.1371/journal.pone.0096351

109. Haraguchi T, Takasaki K, Naito T, Hayakawa K, Katsurabayashi S, Mishima K, et al. Cerebroprotective action of telmisartan by inhibition of macrophages/microglia expressing HMGB1 via a peroxisome proliferatoractivated receptor gamma-dependent mechanism. Neurosci Lett. (2009) 464:151-5. doi: 10.1016/j.neulet.2009.08.043

110. Li LL. Inhibition of RhoA/ROCK Signaling Pathway and its Role in Hemorrhangic Transformation After Cerebral Ischemia/Reperfusion. Chongqing: Chongqing Medical University (2014).

111. Kuhlmann C, Tamaki R, Gamerdinger M, Lessmann V, Behl C, Kempski $\mathrm{O}$, et al. Inhibition of the myosin light chain kinase prevents hypoxiainduced blood-brain barrier disruption. J Neurochem. (2007) 102:5017. doi: 10.1111/j.1471-4159.2007.04506.x

112. Ruan W, Li J, Xu Y, Wang Y, Zhao F, Yang X, et al. MALAT1 upregulator polydatin protects brain microvascular integrity and ameliorates stroke through C/EBP $\beta / \mathrm{MALAT} 1 / \mathrm{CREB} / \mathrm{PGC}-1 \alpha / \mathrm{PPAR} \gamma$ pathway. Cell Mol Neurobiol. (2019) 39:265-86. doi: 10.1007/s10571-018-00646-4

113. Xu M, Yang X, Zeng Q, He H, Lu P, Huang G. BIRC5 is a novel target of peroxisome proliferator-activated receptor $\gamma$ in brain microvascular endothelium cells during cerebral ischemia. Mol Med Rep. (2017) 16:888290. doi: $10.3892 / \mathrm{mmr} .2017 .7750$

114. Yamakawa K, Hosoi M, Koyama H, Tanaka S, Fukumoto S, Morii $\mathrm{H}$, et al. Peroxisome proliferator-activated receptor-gamma agonists increase vascular endothelial growth factor expression in human 
vascular smooth muscle cells. Biochem Bioph Res Co. (2000) 271:571-4. doi: 10.1006/bbrc.2000.2665

115. Arany Z, Foo S, Ma Y, Ruas J, Bommi-Reddy A, Girnun G, et al. HIF-independent regulation of VEGF and angiogenesis by the transcriptional coactivator PGC-1alpha. Nature. (2008) 451:1008-12. doi: 10.1038/nature06613

116. Cimini A, Cerù M. Emerging roles of peroxisome proliferatoractivated receptors (PPARs) in the regulation of neural stem cells proliferation and differentiation. Stem Cell Rev. (2008) 4:293-303. doi: 10.1007/s12015-008-9024-2

117. Arvidsson A, Collin T, Kirik D, Kokaia Z, Lindvall O. Neuronal replacement from endogenous precursors in the adult brain after stroke. Nat Med. (2002) 8:963-70. doi: 10.1038/nm747

118. Zhu C, Zhang X, Qiao H, Wang L, Zhang X, Xing Y, et al. The intrinsic PEDF is regulated by PPAR $\gamma$ in permanent focal cerebral ischemia of rat. Neurochem Res. (2012) 37:2099-107. doi: 10.1007/s11064-0120831-0

119. Bayir H, Fadeel B, Palladino M, Witasp E, Kurnikov I, Tyurina Y, et al. Apoptotic interactions of cytochrome c: redox flirting with anionic phospholipids within and outside of mitochondria. Biochim Biophys Acta. (2006) 1757:648-59. doi: 10.1016/j.bbabio.2006.03.002

120. Islam M. Oxidative stress and mitochondrial dysfunctionlinked neurodegenerative disorders. Neurol Res. (2017) 39:7382. doi: $10.1080 / 01616412.2016 .1251711$

121. Zhang TT. Study on the Relationship Between the Expression of miR-27a and the Regulation of PPAR $\gamma$ in a Rat Model of Cerebral Cortex Neuronal Ischemia. Mudanjiang: Mudanjiang Medical College (2017).

122. Wu J, Cheung W, Tsai Y, Chen Y, Fong W, Tsai H, et al. Ligand-activated peroxisome proliferator-activated receptorgamma protects against ischemic cerebral infarction and neuronal apoptosis by 14-3-3 epsilon upregulation. Circulation. (2009) 119:1124-34. doi: 10.1161/CIRCULATIONAHA.108.812537

123. Ou ZS, Zhao XR, Labiche LA, Roger S, Grotta James C, Oliver H. Neuronal expression of peroxisome proliferatoractivated receptor-gamma (PPARgamma) and 15d-prostaglandin J2-mediated protection of brain after experimental cerebral ischemia in rat. Brain Res. (2006) 1:196-203. doi: 10.1016/j.brainres.2006.04.062

124. Liu HW, Hua Y, Yu YH. The advance of poly ADP-ribose polymerase-1 and poly ADP-ribose polymerase-1-dependentcelldeath in nervoussystem diseases. Int J Anesth Resus. (2013) 34:1051-53+1056. doi: 10.3760/cma.j.issn.1673-4378.2013.11.022

125. Sun Li, Xu YW, Han J, Liang H, Wang N. 12/15-Lipoxygenase metabolites of arachidonic acid activate PPAR $\gamma$ : a possible neuroprotective effect in ischemic brain. J Lipid Res. (2015) 56:502-14. doi: 10.1194/jlr.M053058

126. Xu YW, Sun L, Liang H, Sun GM, Cheng Y. 12/15-Lipoxygenase inhibitor baicalein suppresses PPAR gamma expression and nuclear translocation induced by cerebral ischemia/reperfusion. Brain Res. (2010) 1307:14957. doi: 10.1016/j.brainres.2009.10.038

Conflict of Interest: The authors declare that the research was conducted in the absence of any commercial or financial relationships that could be construed as a potential conflict of interest.

Copyright (c) 2020 Ding, Kang, Liu, Xu and Shao. This is an open-access article distributed under the terms of the Creative Commons Attribution License (CC BY). The use, distribution or reproduction in other forums is permitted, provided the original author(s) and the copyright owner(s) are credited and that the original publication in this journal is cited, in accordance with accepted academic practice. No use, distribution or reproduction is permitted which does not comply with these terms. 